\title{
THE EFFECT OF AMPHOTERICIN B ON THE PROXIMAL TUBULE OF THE RAT KIDNEY
}

STUART R. KLEEMAN 


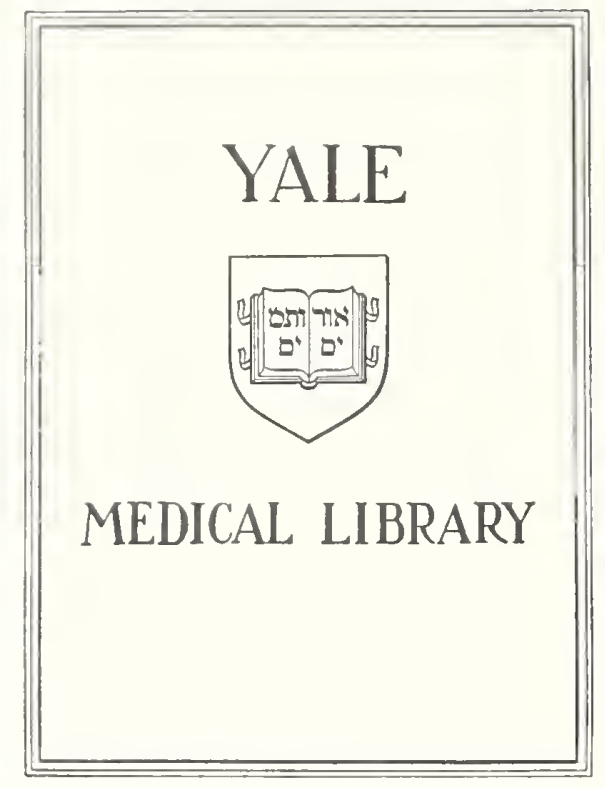



Digitized by the Internet Archive in 2017 with funding from Arcadia Fund 


THE EFFECT OF AMPHOTERICIN B ON THE PROXIMAL TUBULE OF THE RAT KIDNEY

by

Stuart R. Kleeman

A. B. Brown University 1967

\author{
A thesis submitted to the \\ Department of Internal Medicine \\ Yale University School of Medicine \\ in partial fulfillment \\ of the requirements for the degree of \\ Doctor of Medicine
}

April 1971

New Haven, Connecticut

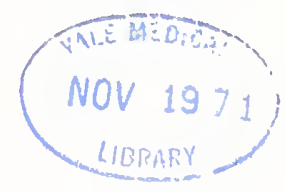



To Dr. John P. Hayslett, for his guidance, patience and advice in many matters for the past four years.

To Dr. Michael Kashgarian, for his instruction, both technical and theoretical, and the demonstration that mastery of the machinery is possible.

To Dr. Edward J. Weinman, for his constant encouragement.

To Dr. Franklin H. Epstein, for his inspiration and the introduction to my other mentors.

To Mr. Richard Whittaker and Mrs. Dorothy Smith, for their valuable technical instruction and assistance.

To Mrs. Lena DelCorte, for her secretarial assistance. And finally, to my wife, Terry, for her devotion, confidence and an uncanny ability to help me past my minor disasters. 

TABLE OF CONTENTS

Introduction $\ldots \ldots \ldots \ldots \ldots \ldots \ldots \ldots \ldots \ldots$

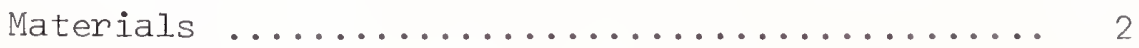

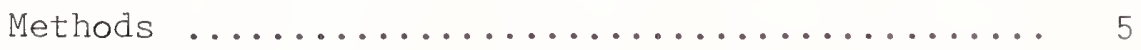

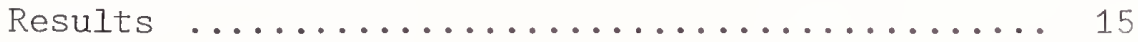

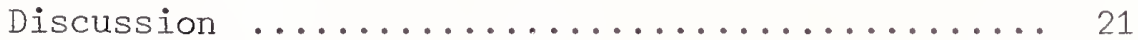

Summary $\ldots \ldots \ldots \ldots \ldots \ldots \ldots \ldots \ldots \ldots \ldots \ldots \ldots$

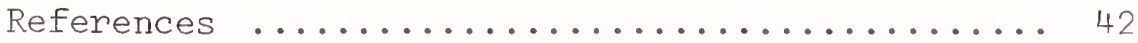


In the field of renal physiology, many investigators have recently been attempting to evaluate and clarify the mechanisms which control the reabsorption and the ultimate urinary excretion of sodium. These mechanisms are vital to fluid and electrolyte homeostasis, for by varying the excretion of sodium, the principle cation of the extracellular fluid, the organism is able to influence the volume of this fluid compartment and control for differing levels of sodium intake.

Among the parameters under investigation in the control of sodium reabsorption are circulating hormones, changes in peritubular physical factors and the distribution of renal blood flow to functionally different parts of the renal cortex. In order to be accessible to the influence of these factors, however, sodium must cross the luminal membrane into the epithelial cell and be available to the sodium pumping apparatus. The effect of possible variations in luminal membrane permeability has been, thusfar, relatively neglected.

-This study was an attempt to clarify the role of this barrier in sodium reabsorption by altering its permeability. Using micropuncture techniques, the lumen of the proximal tubule of the rat kidney was perfused with amphotericin B, a polyene antibiotic known to increase the permeability of membranes in many in vitro systems, and the changes in sodium and fluid reabsorption were measured. 
1. Experimental Animals. Adult male Sprague-Dawley rats weighing 220-410 gm were obtained from Camm Research, Wayne, N.J., and Charles River, No. Wilmington, Mass. They were maintained in individual cages on Purina chow and tapwater, ad libitum. Food and water were not restricted prion to the induction of anesthesia at the time of each experimental study.

2. Construction of micropipettes. Double-barreled micropipettes were prepared from glass capillary tubing, approximately $1 \mathrm{~mm}$ in external diameter that had been washed in concentrated sulfuric acid and air dried. Two 15-20 cm lengths of tubing were manually pulled and twisted over a small flame resulting in union of the two in a pattern of 2-4 tight spirals. The tubing was heated at the point of union and pulled apart by an automatic micropipette puller (Industrial science Associates, Inc., Ridgewood, N.Y.). In this way, a double-barreled micropipette was obtained with a common, tapered tip. At the mid-point of the micropipette, one barrel was gently heated and manually bent to an angle of $80^{\circ}$, so that each barrel could be individually filled. The tip of each micropipette was viewed at $100 \mathrm{x}$ under a monocular microscope fitted with a filar eyepiece micrometer and manually broken off with a forceps to an outside diameter of 7-10 $\mu$. The micropipettes were held in a pipette holder on a micromanipulator (Model 5003, Brinkmann Instruments, Inc., Great Neck, N.Y.), and the tips were beveled against a carborundum grinding wheel (Model 37C 320 LIIV, Norton Abrasives, Teterboro, N.Y.) to an angle of approximately $30^{\circ}$. Each micropipette was examined microscopically to guarantee a smooth, patent, beveled tip of appropriate dimensions. 


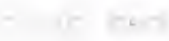

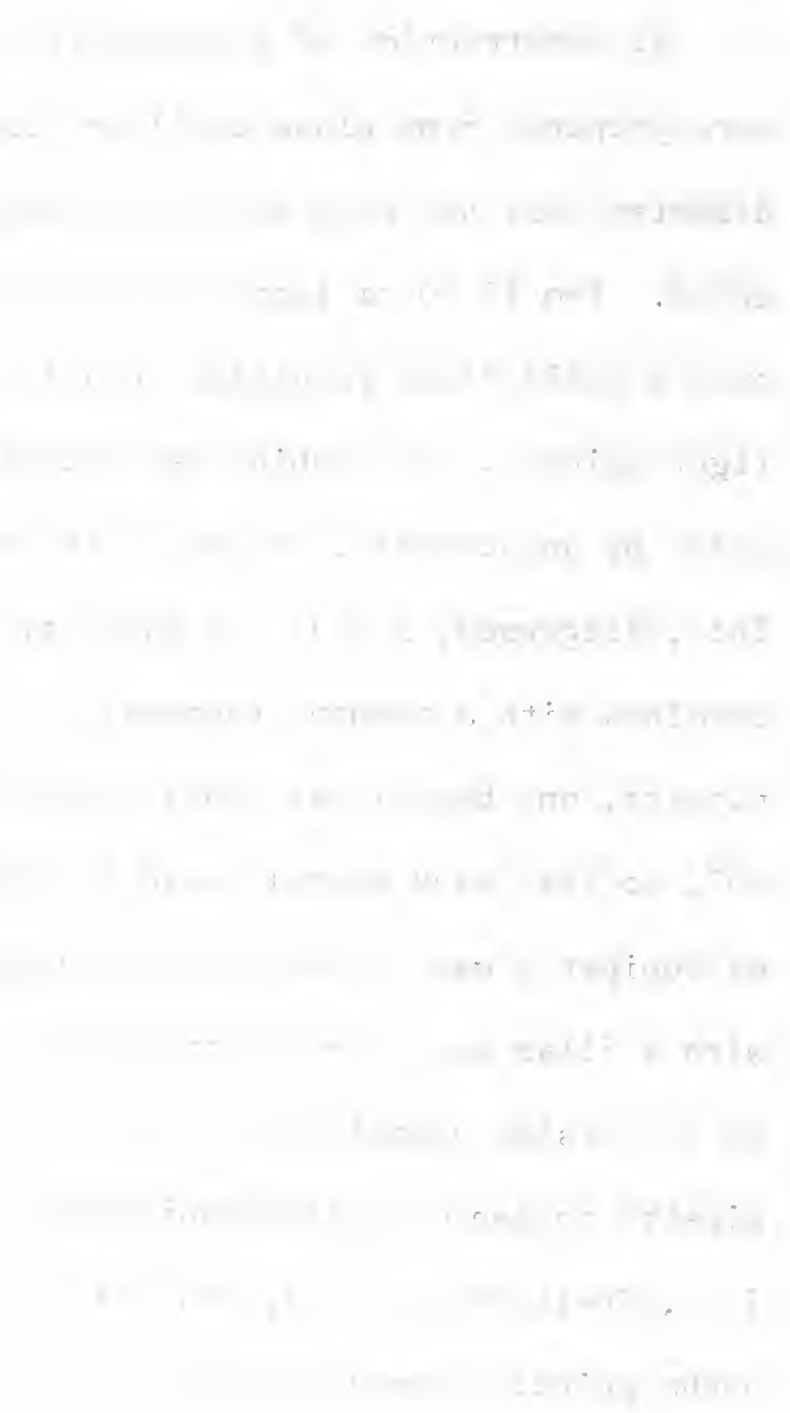


3. Solutions and Routes of Administration

A. Anesthesia. Inactin (Chem. Fabrik. Promonta, Hamburg, Germany) was made up daily in $154 \mathrm{mMNaC1}$ at a concentration of $80 \mathrm{mg} / \mathrm{ml}$. Rats were injected intraperitoneally at a dosage of $160 \mathrm{mg} / \mathrm{kg}$, body weight. This agent produced a stable state of general anesthesia which was maintained for the duration of the acute experiments ( 2 to 4 hours). Additional increments of anesthetic were not required.

B. Infusion Solutions Intravenous solutions were administered via indwelling polyethylene catheters placed in the external jugular veins.

i. 154 mMNaC1 was made up in distilled water and used to replace surgical losses and provide maintenance hydration during the entire course of each experiment.

ii. $10 \%$ Lissamine green was made up in distilled water and injected periodically to measure proximal tubule transit times.

Intratubular- The double-barreled micropipettes were filled just prior to use with an aqueous test solution in the bent arm and a filtered suspension of Sudan black (for photographic contrast) in castor oil in the straight arm. The test solutions consisted of:

i. $154 \mathrm{mMNaC} 1$

ii. Amphotericin B, as the solubilized Fungizone preparation (E.R. Squibb and Sons, New York, N.Y.), was dissolved in 154 mMNaC1 to final concentrations of:

amphotericin B, $50 \mu \mathrm{g} / \mathrm{ml}$

sodium desoxycholate, $41 \mathrm{\mu g} / \mathrm{ml}$ sodium phosphate buffers, $25 \mu \mathrm{g} / \mathrm{ml}$.

These amounts resulted in an addition of $0.97 \mathrm{mOsm} /$ Liter to the isotonic saline (a $0.32 \%$ increase in osmolarity). 
$$
\text { . }
$$ 
iii. A third solution containing all the constituents of Fungizone with the exception of amphotericin B was made up in 154 mMNaC1 to the same concentration as in the amphotericin B test solution (ii).

Solutions ii. and iii. were prepared weekly and refrigerated at $4^{\circ} \mathrm{C}$ until used. 



\section{METHODS}

1. Surgical Preparation

After the induction of anesthesia with Inactin, the neck, abdomen, and left flank were shaved. The animal was placed supine on an electrically heated board with the temperature controlled by a type 116 Powerstat (Fisher Scientific, New York, N.Y.) and body temperature monitored with an esophageal temperature probe (Tele-thermometer, VS1, Yellow Springs Co., Inc., Yellow Springs, Ohio) and maintained at $37^{\circ}$ $38^{\circ} \mathrm{C}$.

A tracheostomy was performed with a $3-4 \mathrm{~cm}$ segment of tapered clay Adams PE 260 polyethylene tubing inserted in the trachea, secured with 3-0 surgical silk and cut as short as practicable to limit respiratory dead space. One external jugular vein was cannulated with Clay Adams PE20 polyethylene tubing filled with 154 mMNaC1 and secured with 4-0 surgical silk. The urinary bladder was exposed through a suprapubic incision, and a short length of Clay Adams PE50 polyethylene tubing with a heat-flanged tip was secured in the bladder with 3-0 surgical silk.

A vertical midline incision was made in the abdominal skin and the recti divided from approximately $1 \mathrm{~cm}$ cephalad to the bladder incision to the xiphoid process. A left subcostal incision was carried from the midline to the posterior axillary line, and the animal was moved onto its right side. Overlying loops of bowel were gently retracted from the left upper quadrant, and the left kidney was visualized.

Using two pairs of small forceps, the perinephric fat and fibrous renal capsule were carefully stripped away from the superficial parenchyma leaving the entire cortical surface exposed (1). The kidney was placed in a small rectangular plexiglas cup which contained a broad 


\section{ris

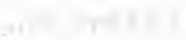

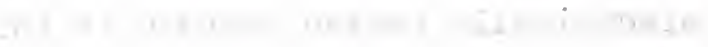

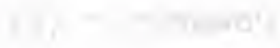
1. n.
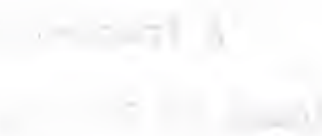

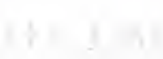

inte

if if thene

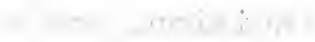

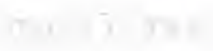

$x^{2}+2=3$ 
notch on one side to accomodate the renal pedicle in onder to avoid vascular embarassment to the kidney. The cup was lined with cotton fluff soaked with mineral oil to immobilize the kidney and reduce respiratory movement and vascular pulsations. A brass handle attached to the cup was secured in a thumb-screw holder on the animal board, and the angle of the handle and the cotton packing were adjusted so as to leave the surface of the kidney as close to horizontal as possible. The skin and muscle edges were retracted with modified safety pins anchored to the cork surface of the animal board, and the kidney was covered with mineral oil, at room temperature, which was replenished at ten minute intervals.

$154 \mathrm{mMNaC1}$, in an amount equal to $1 \%$ of the animal's body weight, was infused over an 8-12 minute period by a compact Infusion Pump (Model 975, Harvard Apparatus Co., Inc., Dover, Mass.) to replace surgical fluid losses. A $1.2 \mathrm{ml}$ per hour infusion was maintained for the remainder of the experiment.

The animal, lying on the heated animal boand, was placed on an adjustable stage (Big Jack, Precision Scientific Co., Chicago, Ill.) under a stereomicroscope (Model 570, 0.7-4.2 X, American Optical Co., Buffalo, N.Y.). The entire exposed surface of the kidney was visualized at $84 \mathrm{X}$ with illumination from a 100 watt zirconium arc lamp with heat reflecting glass filters (Paul Rosenthal, Inc., Great Neck, N.Y.), and individual surface tubules could be clearly visualized.

2. Experimental Design

Experiments lasted from 2-4 hours, including the time required for surgical preparation. During the course of each experiment, proximal tubule transit times were estimated at 20-30 minute intervals to assess the viability of the preparation. From one to six proximal 
tubules were selected on the basis of criteria for length, shape, and accessibility by the micropipette, and each tubule was blocked with castor oil, perfused with an aqueous solution and photographed no more than twice. During the course of the reabsorption of each aqueous droplet, from three to six photomicrographs were taken at three second intervals, and at the conclusion of each experiment, the film was developed, enlarged, and printed under controlled conditions. All prints were grouped into ordered sequences of individual droplets, and each sequence received a random code number. All droplets were measured and reabsorptive half-times $\left(t^{\frac{1}{2}}\right)$ were calculated without the observer knowing the composition of the droplet under consideration. After the calculation of all $t^{\frac{1}{2}} \mathrm{~s}$, the code was revealed and the droplets were grouped according to the nature of the test solution. Statistical analysis was performed, and the differences in the calculated mean $t^{\frac{1}{2} s}$ were compared using student's t test.

3. Proximal Tubule transit times.

In order to evaluate the condition of the preparation as a whole and test the patency of individual proximal tubules, a modification of Steinhausen's (2) method for distinguishing proximal from distal tubules on the kidney surface was employed.

When viewed through the microscope with proper illumination, proximal tubular loops can be distinguished from the much rarer distal tubular loops by the bright band, representing the brush border, on the luminal surface of cells of the proximal convolution, which is virtually absent in the distal tubule. Only the middle thind of the proximal convoluted tubule is present on the kidney surface, and the terminal superficial segments of this portion of several proximal tubules are seen to converge in groups surrounding single efferent 
arterioles in a series of "star" or "rosette" conformations. This conformation represents the point at which tubular fluid has traversed 55$60 \%$ of the proximal tubule and is about to desend into the contex in the pars recta (3).

To estimate proximal tubule transit time, the surface was observed while $0.5 \mathrm{ml}$ of $10 \%$ Lissamine green was rapidly injected intravenously with a gastight syringe (\#1002, Hamilton Co., Whittier, California). According to the modification of Gertz, et al. (4), the transit time was measured from the occurrence of the initial "green blush" of the renal surface, resulting from the filling of surface vasculature and Bowman's capsule and indicating the entrance of dye into the proximal tubule, to the time when the filtered dye had filled the last of a group of tubules forming a "rosette". These intervals which were usually 9-11 seconds were used as the index of viability of the kidney. If and when this transit time became grossly prolonged (greater than 15 seconds), the experiment was terminated.

4. Stationary Microperfusion.

Purpose. The technique of stationary microperfusion of proximal tubule segments, also known as the "split oil droplet" method, was used to evaluate net fluid efflux under control and experimental conditions.

Theoretical Formulation. In the original description of this method, Gertz (5) demonstrated that when a column of oil filling the proximal tubular lumen was split by a droplet of saline, the progressive net reabsorption of the saline was accompanied by the convergence of the ends of the oil columns. The regression in the length of the droplet, therefore, was considered to be directly proportional to the rate of fluid reabsorption. The radius of any given droplet was considered to be constant all along the droplet and constant during the period of 

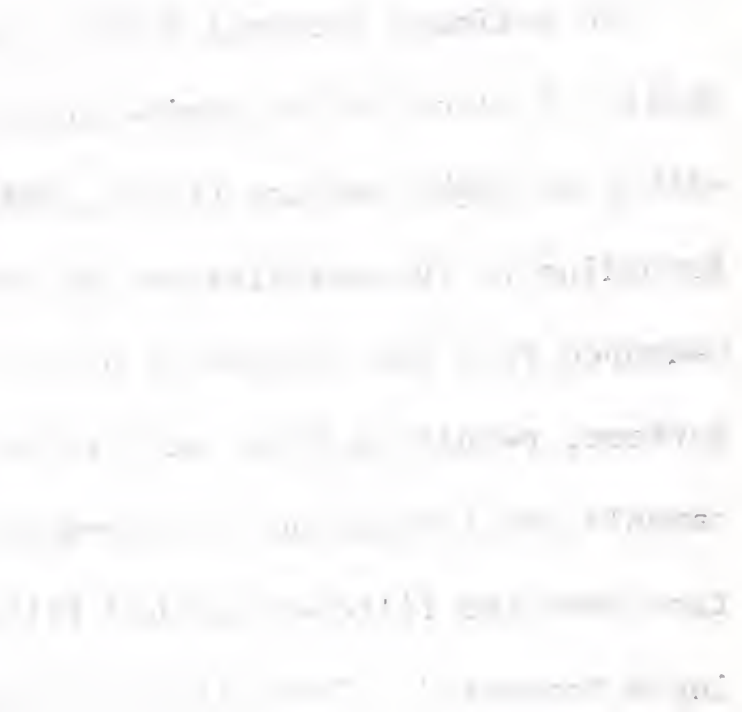

, 1 1 $-1$ 
droplet shrinkage. The relationship between the length of the droplet and time was demonstrated to be semilogarithmic and can be expressed as: (1) $\ln \left(\frac{1(t)}{1(0)}\right)=m t$

where $1(t)=$ the droplet length at time, $t$,

$1(0)=$ the initial droplet length,

$m=$ the slope of the semilogarithmic regression,

$\mathrm{t}=\mathrm{time}$.

by rearranging (1),

(2) $\ln \left(\frac{\frac{1(t)}{1(o)}}{t}\right)=m$.

Procedure. The double barreled micropipettes were filled to the tips with castor oil and an aqueous test solution and placed in a Leitz micromanipulator. A compressed air line was connected to the straight arm containing the castor oil, and a $50 \mathrm{ml}$ glass syringe was attached via, polyethylene tubing to the bent arm with the aqueous solution. The kidney surface was scanned in order to locate a segment of proximal tubule which appeared to be grossly straight, with paralled sides, totally on the surface, approximately 3-5 tubular diameters in length, and aligned approximately in the orientation of the micropipette. The micropipette tip was moved as close to the end of a length of tubule as possible, and lowered at an angle between $15^{\circ}$ and $40^{\circ}$ to the horizontal, far enough to barely depress the tubular epithelium. The tubule was punctured with a short, brisk motion along the axis of the micropipette leaving the openings of both barrels entirely within the lumen of the tubule. Castor oil was injected in amounts sufficient to block tubular flow, and the oil was followed by the infusion of the test solution droplet. It was usually necessary to move the aqueous droplet away from the pipette tip by injecting more oil. 


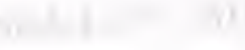

$$
\begin{aligned}
& 1+2+1 \\
& 1
\end{aligned}
$$

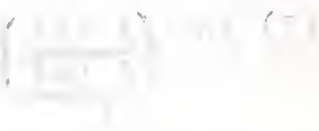

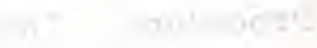

$$
\begin{aligned}
& =11, \quad 0011+1
\end{aligned}
$$

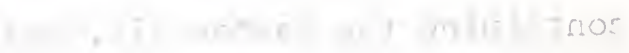$$
\text { - }
$$ 
The sequential decrease in the length of the droplet, as reabsorption progressed, was recorded by time-sequence photomicrography, performed on Tri-X film (EI 1200, Eastman Kodak, Rochester, N.Y.) with a Nikon F 35 mm camera with electric motor drive (Model F-36) mounted on the ocular of the microscope. The camera and a home-made flash illuminator, powered by a battery pack, were triggered at three second intervals by a Nikon intervalometer (Model NCl) until manually terminated when the droplet was reabsorbed. The exposed film was developed in Acu-1 film developer (Acufine, Chicago, Ill.), diluted 1:5 in water, for eight minutes at $75^{\circ} \mathrm{F}$, enlanged and printed on Kodabromide $\mathrm{F}-4$ paper (Eastman Kodak, Rochester, N.Y.). All prints were made at the same magnification (Fig. 1).

5. Droplet Measurement.

In order to reduce observer bias, the prints were grouped as sequences of individual droplets, and each sequence given a randomly selected code number. The photographs were saved until all the droplets could be measured at a single sitting, without the observer having the knowledge of the composition of the droplets.

The measurements were performed using a pair of drafting dividers. The shortest distance between the menisci of the oil columns was measured, compared with an arbitrary scale, and recorded as the droplet length, I, for each time, t, $(0,3,6,9,12$ seconds, etc.) as seen in Table 1.

The slope of the regression of length for each time interval was calculated with the Programma 101 digital computor (Underwood Olivetti, New York, N.Y.) using formula (2). The slopes for all time intervals were averaged, yielding the mean slope of each droplet sequence. When the original droplet has shrunken to one-half its initial length, $\frac{1(t)}{1(o)}$ is equal to 0.5 . The time required for this degree of reabsorption is 
11 Figure 1 Sequence of photographs depicting saline
droplet reabsorption

O Sec $3 \mathrm{Sec} \quad 6 \mathrm{Sec} \quad 9 \mathrm{Sec} \quad 12 \mathrm{Sec}$ 
12

Table 1 Sample Droplet Measurements

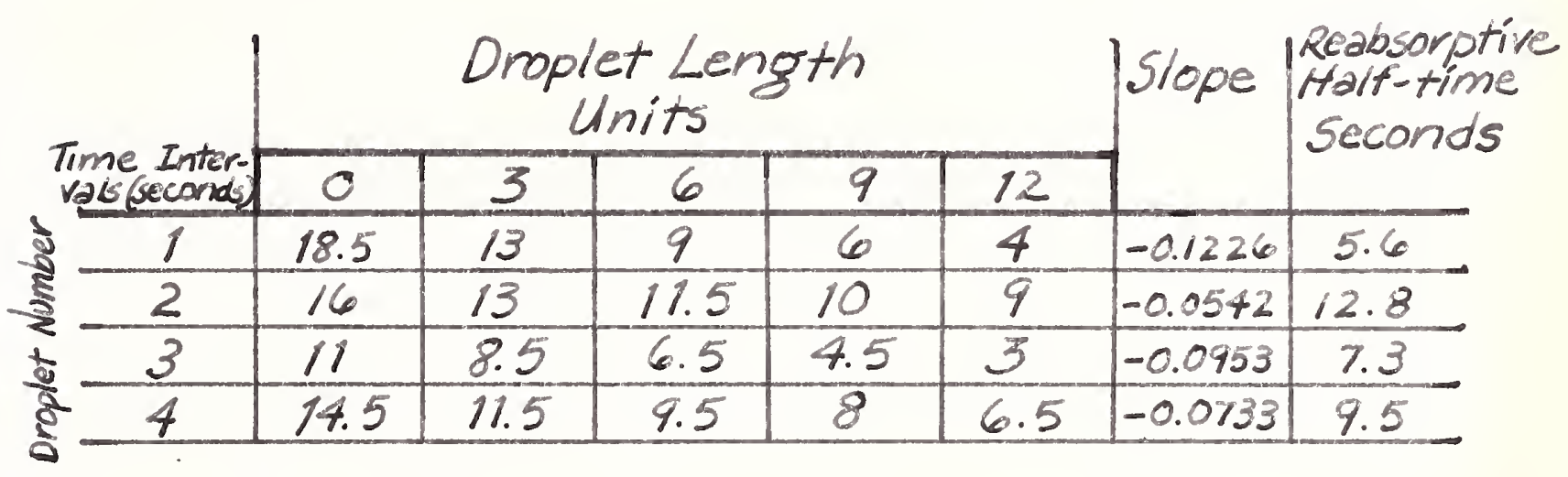





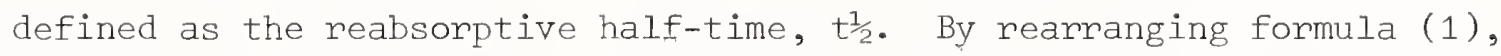
and substituting the appropriate values,

(3) $\frac{\ln (0.5)}{m}=t^{\frac{1}{2}}$

and since $\ln (0.5)=-0.693$

(4) $t^{\frac{1}{2}}=\frac{-0.693}{m}$.

Using formula (4), a $t^{\frac{1}{2}}$ for each droplet was calculated. The code was broken at the conclusion of the droplet measurements and $t \frac{1}{2}$ calculations, and the droplets were grouped according to their composition.

6. Statistical Calculations.

The $t \frac{1}{2} s$ were plotted against the initial droplet lengths, 1 (o) to determine whether there was a correlation between these factors which might bias the results. A coefficient of correlation was calculated for the saline control data and recalculated after arbitrary limits had been placed on 1 (o) to provide similar distributions of 1 (o) for all experimental groups. The mean, standard deviation and standard error of each revised group (with limits on 1 (o)) were calculated, and the mean $t^{1} \frac{1}{2}$ for each group was compared with the other two groups using student's $t$ test to determine the significance of calculated differences.

In order to express the reabsorptive capacities in more quantitatively descriptive terms than $t^{\frac{1}{2}}$, the net flux of water was calculated (6). Water flux (Jv) is equal to the change in volume per unit surface area per unit time. If the droplet is considered a regular cylinder with its radius expressed as $r$ :

(5) $\mathrm{Jv}=\frac{\left(\pi r^{2}\right) \mathrm{d} l}{(2 \pi r 10) \mathrm{dt}}$,

where lo = initial length of droplet

$t=$ time (seconds). 

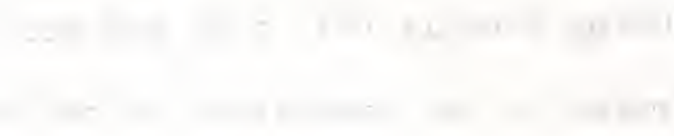

$1+1-$

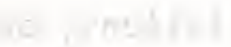

1410 
Integration of expression (5) gives:

$$
\begin{aligned}
& \text { (6) } \mathrm{JV}=\ln \left(\frac{1}{10}\right) \cdot \frac{\mathrm{r}}{2 \mathrm{t}} \cdot \\
& \text { If } t=\mathrm{t} \frac{1}{2}, \ln \left(\frac{1}{10}\right)=\ln (0.5)=-0.693
\end{aligned}
$$

and substituting in (6):

$$
\text { (7) } J v=\frac{-0.347 r}{t \frac{1}{2}} \text {. }
$$

The actual tubular radius was established by measuring oil filled tubules with a stage micrometer photographed at the same magnification as the droplets. By substituting the calculated mean tubular radius and $t \frac{1}{2}$ for each group into formula (7), the net water flux for each experimental group was obtained and expressed as $\mathrm{mm}^{3} / \mathrm{mm}^{2}$ per second. 



\section{RESULTS}

1. Analysis of the stationary microperfusion method as an estimate of net sodium reabsorption - The relationship of initial length and reabsorptive half-time.

All of the acceptable droplets (straight, parallel lengths of proximal tubules, entirely on the surface) were measured and $t \frac{1}{2} s$ were calculated for all the experimental groups. Since the saline control group had the fewest experimental manipulations, by virtue of the simplicity of the composition of the droplet, it was elected to evaluate the effect of initial length on reabsorptive half-time in this group. When these $t^{\frac{1}{2}}$ s were plotted against 1 (o), some impression of the effect of initial droplet length on the calculated reabsorptive capacity becomes readily apparent (Fig. 2). Merely by inspection, it can be appreciated that at shorter $1(0)$, t $\frac{1}{2}$ tends to be of much shorter duration. A coefficient of correlation for these 40 original droplets from 14 different experimental animals over a range of initial lengths of 6 to 19.5 units was calculated to be $r=0.4708$ which was significantly positive at $\mathrm{p}<0.01$. Since in each of the three groups, there was a similan distribution of initial lengths between 9 and 20 units, these limits were arbitrarily placed on the range of initial droplet length. The coefficient of correlation was recalculated for this revised group of 33 droplets at $\mathrm{r}=0.2755$ which was not significantly positive with p>0.1 (Fig. 3). This set of limits was imposed on each experimental group to reduce the influence of initial length on reabsorptive halftime, and it reduced the number of droplets in the desoxycholate group from 47 to 33 in 12 animals and in the amphotericin B group from 39 to 23 in 11 animals. 
Figure 2 Correlation of initial droplet length and reabsorptive half-time in saline control droplets

(all measured droplets included)

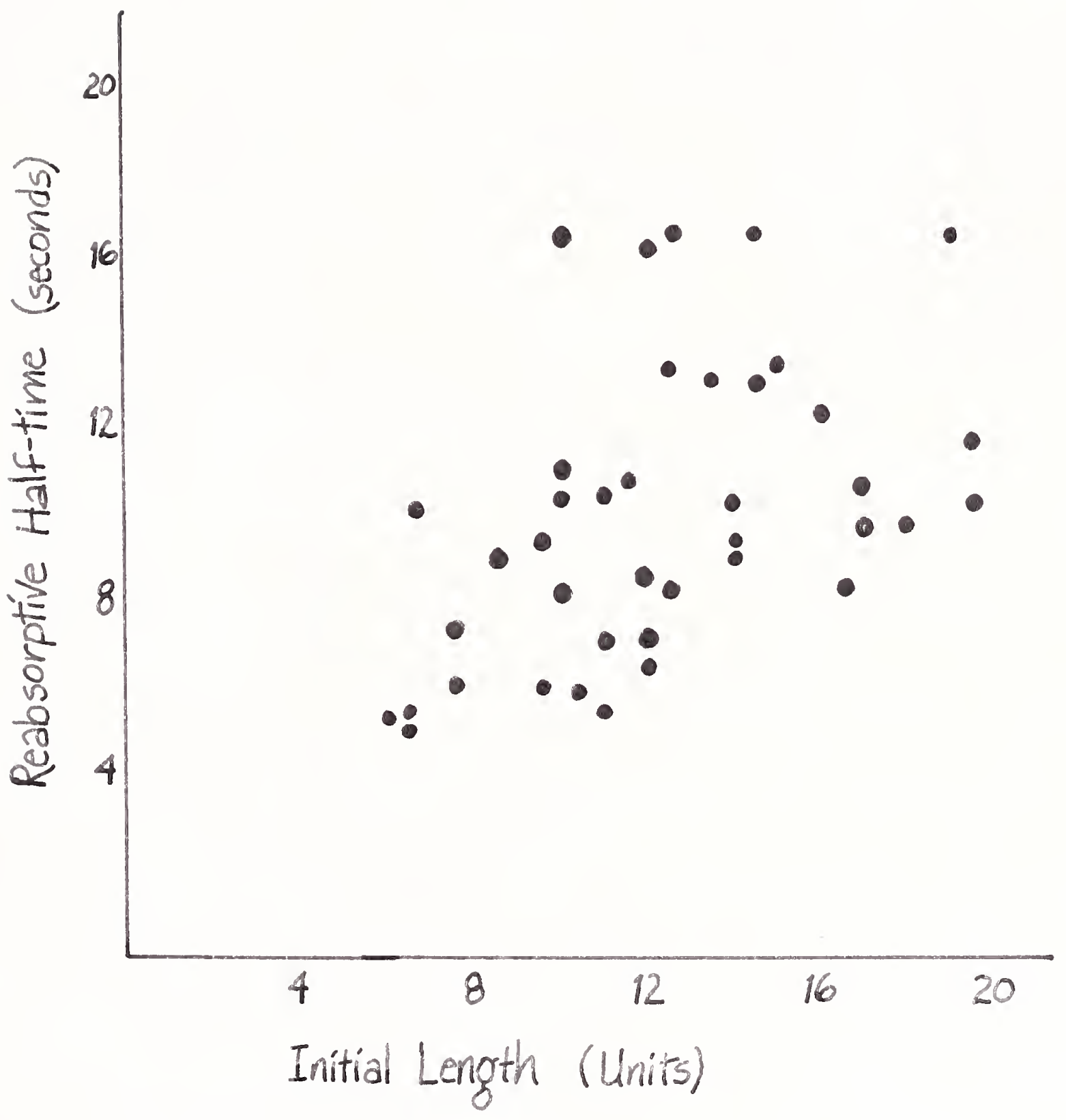

Coefficient of Correlation:

$r=0.4708, p<0.01$ 


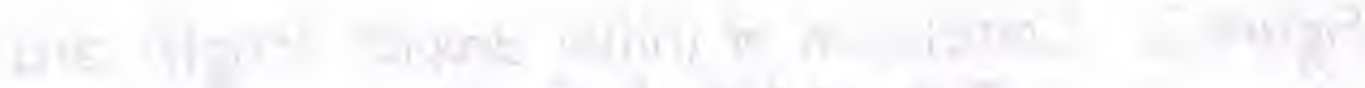

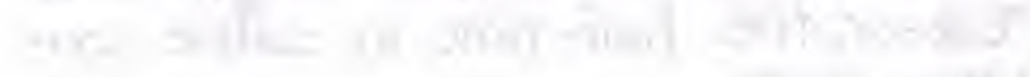

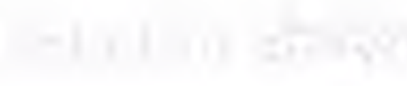

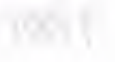

$+$

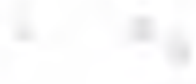

IIn

tent

4

$+$

$$
+2
$$

$=$

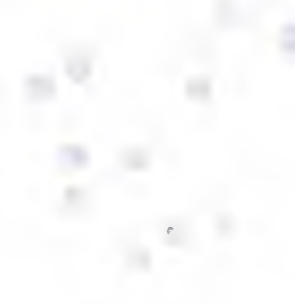


Figure 3 correlation of initial droplet length and reabsorptive half-time in saline control droplets

Conly droplets with initial length between 9 and 20 units includeds)

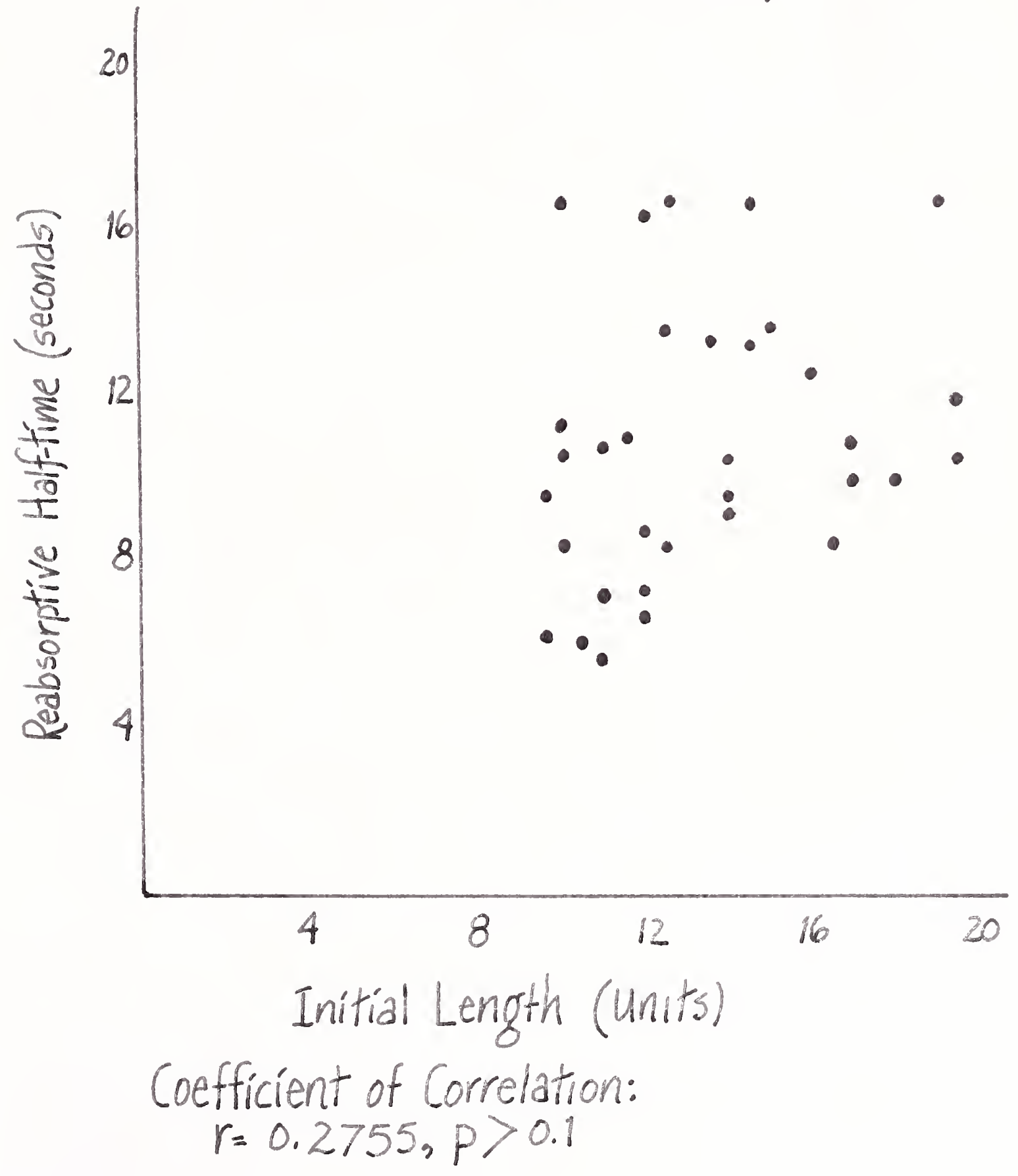




\section{$\sin 67$}

$=$

1
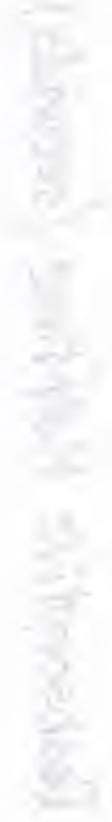
2. Effect of the droplet composition on reabsorptive half-times. When $t \frac{1}{2} s$ were calculated in each group within the aforementioned

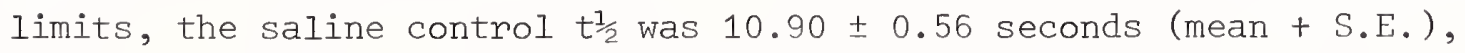
the desoxycholate mixture was $9.44 \pm 0.60$ seconds and the amphotericin $B$ was $7.54 \pm 0.61$ seconds (Table 2). A comparison of the calculated mean reabsorptive half-times demonstrates that with amphotericin B in the droplet, the $t \frac{1}{2}$ was significantly shorter than with saline $(p<0.001)$ or desoxycholate $(p<0.02)$ in the droplets. It also appeared that the desoxycholate mixture alone may have caused more rapid reabsorption than the saline, although the difference was of borderline significance $(p<0.05)$. Nevertheless, amphotericin B definitely appears to have an effect on tubular reabsorption when this agent is in contact with the luminal membrane of the rat proximal tubule.

3. Calculation of net water flux.

When measured with the stage micrometer, the average internal radius of the oil filled tubule was $17.8 \pm 0.3 \mu$. Net water fluxes for each experimental group were calculated, based on this average value, and were found to be: $-5.67 \times 10^{-4} \mathrm{~mm}^{3} / \mathrm{mm}^{2} / \mathrm{sec}$. for saline, $-6.54 \times 10^{-4}$ $\mathrm{mm}^{3} / \mathrm{mm}^{2} / \mathrm{sec}$. for the desoxycholate, and $-8.19 \times 10^{-4} \mathrm{~mm}^{3} / \mathrm{mm}^{2} / \mathrm{sec}$. for the amphotericin B group (Table 3 ). The negative values indicate net water efflux. 
Table 2 Effect of amphotericin B and desoxycholate on reabsorptive half-time

\begin{tabular}{|c|c|c|c|}
\hline \multirow{4}{*}{$\begin{array}{l}\text { Saline } \\
\text { Desoxycholate } \\
\text { Amphoteriain B }\end{array}$} & \multicolumn{2}{|c|}{ 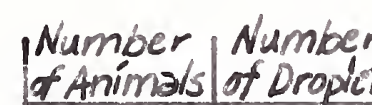 } & $\begin{array}{l}\text { Reabsorptive } \\
\text { Half-time (seconds) }\end{array}$ \\
\hline & 14 & 33 & $10.90 \pm 0.56$ \\
\hline & 12 & 33 & $9.44 \pm 0.60$ \\
\hline & 11 & 23 & $7.54 \pm 0.61$ \\
\hline
\end{tabular}

Significance of differences:

Saline-Amphotericin B, $p<0.001$

Saline-Desoxycholate, $P<0.05$

Desoxycholate-Amphotericin B, $p<0.02$

* values represent means \pm standard errors 

20

Table 3 Effect of amphotencin B and desoxycholate on net water flux

Reabsorptive Net Water Flux
Halftimes (seconds)

Saline

\begin{tabular}{l|l|l|}
\hline Desoxycholate & 10.90 & $-5.67 \times 10^{-4}$ \\
\hline Amphotericin B & 9.44 & $-6.54 \times 10^{-4}$ \\
\hline & 7.54 & $-8.19 \times 10^{-4}$ \\
\hline
\end{tabular}

* negative values indicate net flux 


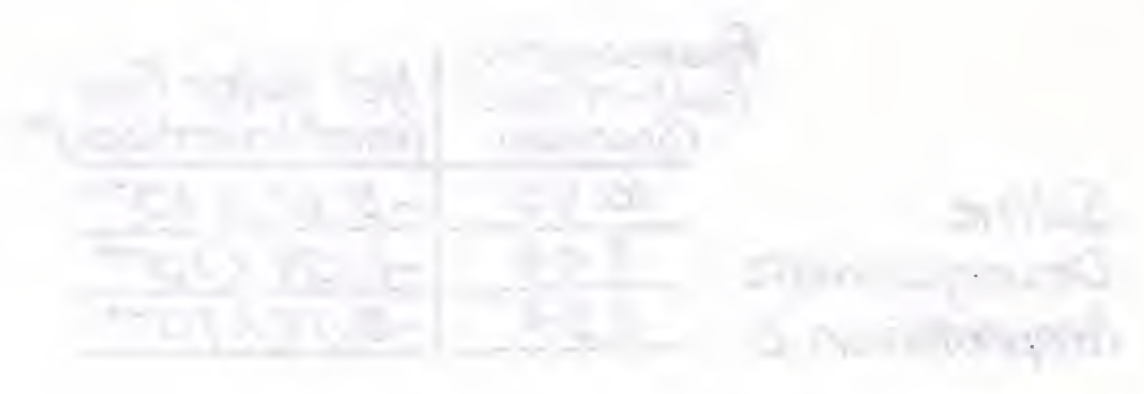




\section{DISCUSSION}

Reabsorption of sodium in the proximal tubule.

The experiments were designed to evaluate the influence of permeability characteristics of the plasma membrane of the proximal tubular epithelial cell on net sodium efflux. In particular, the role of the luminal membrane as a rate limiting factor in sodium entry into the cell was studied. Amphotericin B was used in this in vivo preparation to effect an increase in the permeability of the luminal membrane, since recent studies have demonstrated that when this agent is applied to the mucosal surface of many epithelial structures in in vitro preparations, there is an increase in permeability of the affected membrane.

The importance of such cellular factors as membrane permeability in the regulation of net sodium reabsorption is best understood when studied in relationship to other factors which are known or thought to influence sodium reabsorption in the proximal segment of the nephron and in the kidney as a whole.

From the early work of pioneers in micropuncture technique, Walker and his associates (7), it can be seen that approximately two-thirds of the glomerular filtrate is absorbed along the course of the mammalian proximal convolution. This process occurs while there are no osmotic or sodium concentration gradients between the tubular fluid and plasma. These basic findings have been repeated by several investigators and are now accepted principles upon which the understanding of renal function is based $(8,9,10)$. The mode of transfer of this large percentage of glomerular filtrate is widely believed to be based on the active transport of ionic sodium with the water following passively along the osmotic gradient produced by this solute shift. From 


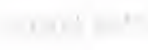

r.

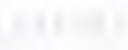

14. 1 
electrochemical determinations across the proximal tubule, it has been shown that sodium is actively pumped out of the tubule since it can be demonstrated that sodium passes from lumen to peritubular fluid against an electrochemical gradient even when a poorly reabsorbable solute remains in the tubular lumen as during mannitol diuresis $(8,10,11)$. It is further known that renal sodium reabsorption and oxygen consumption are linearly related, so that each mole of oxygen used is associated with the reabsorption of $20-30 \mathrm{mEq}$ of sodium, thus establishing the energy dependent nature of sodium extrusion $(12,13)$.

For purposes of highlighting reabsorptive mechanisms, different experimental conditions can be imposed which vary the amount of sodium that is reabsorbed by the proximal tubule and ultimately excreted in the urine. It is important to understand what factors have been delineated which mediate this control of proximal tubular fluid reabsorption. The first variable to be investigated is the glomerular filtration rate, a parameter which controls the amount of solute presented to the proximal tubule. Lindheimer, et al. (14) demonstrated that an increase in glomerular filtration, independent of a change in extracellular volume, was related to only minimal increases in sodium excretion. This finding is consistent with the concept of glomerulotubular balance established by Homer Smith (15), wherein the nephron maintains a balance between glomerular filtration and tubular reabsorption. It was felt that the proximal tubule compensated for an increased sodium load by increasing its absolute reabsorption so that at any point along the tubule, the percentage of glomerular filtrate remaining was unchanged from the control situation (16). But other studies have shown that this proximal tubular compensation is not perfect under all conditions $(4,17)$, and that glomerulotubular balance is not an unvarying, inherent property 
of the nephron. This compensatory mechanism seems totally absent when the proximal tubule is perfused in situ by a pump, bypassing the glomerulus (18). In this case absolute sodium reabsorption remains the same over wide variations in perfusion. These studies tend to indicate that glomerulotubular balance does exist under non-diuretic conditions in the intact nephron, but alterations in extracellular volume on renal blood flow and changes in filtration independent of the peritubular environment can upset their relationship.

The second factor classically considered to control sodium reabsorption is the effect of adrenal mineralocorticoids. If the composition of the urine is examined before and after administration of aldosterone, it becomes apparent that the changes occurring in electrolyte excretion are primarily a result of increased exchange of sodium for potassium in the distal tubule (19). It has been shown, however, that aldosterone also exerts some effect on proximal tubular function as, in adrenalectomized animals, proximal tubular reabsorption is decreased from control levels, but returns to normal after the animals receive aldosterone $(20,21)$.

Recently, micropuncture methods have been extensively used to elucidate other factors involved in the control of sodium reabsorption. Tubular volume and geometry have been investigated in several situations. Gertz, et al. (4) presented evidence that total transtubular reabsorption is a function of the square of the tubular radius. The influence of tubular geometry was further reinforced by the studies of Rector and associates (22) who found proximal tubular reabsorption proportional to cross-sectional area $\left(\pi r^{2}\right)$ under stopped flow conditions. Schnermann and his colleagues (23) demonstrated that even under conditions of water diuresis, the reabsorptive rate is linearly related to tubular volume, which is also a function of the square of the tubular radius. 
Lewy and Windhager (24), however, found that by increasing the peritubular capillary pressure via partial constriction of the renal vein, they produced a decrease in sodium reabsorption which was not accompanied by a proportional decrease in the square of the tubular radius. These experiments indicate that tubular volume is not the sole determinant of reabsorptive rate, and that under certain experimental conditions, such as those dealing with alterations in renal hemodynamics, there may be changes in reabsorption independent of variations in tubular geometry. In the studies of Earley and his associates $(25,26,27)$, it was shown that sodium excretion is increased by induced renal vasodilatation, varies in the same direction as renal perfusion pressure, and is decreased by infusion of hyperoncotic albumin. When the factor of peritubular capillary hydrostatic pressure was evaluated in micropuncture studies, it was shown that increased pressure was associated with decreased fluid reabsorption (24). Experiments in which hypertension was acutely induced by carotid artery ligation and bilateral vagotomy, demonstrated that the elevation in systemic blood pressure was associated with increased urine flow and sodium excretion (28). Micropuncture techniques demonstrated definitely decreased fluid reabsorption in the proximal tubules associated with increased hydrostatic pressure within the tubular lumen. The authors assumed that there was an equivalent increase in peritubular capillary pressure which was felt to mediate the reduced reabsorption from the tubule.

The factor of colloid oncotic pressure was investigated by perfusing peritubular capillaries with solutions of varying colloid concentrations and performing free-flow and stationary perfusion micropuncture on the accompanying proximal tubules (29). With this technique, Spitzer and Windhager demonstrated that fluid reabsorption from the proximal 
tubule varies directly with peritubular oncotic pressure. These studies all tend to lend credence to Earley's stress on peritubular determinants of sodium reabsorption and excretion, but the relative importance of hydrostatic pressure and colloid oncotic pressure to one another in the control of reabsorption is still subject to question. The mode of action of these influences on reabsorption is also hypothetical at this point, although both Koch, et al. (28) and Windhager's group $(24,29)$ have suggested increased back diffusion of sodium across the peritubular membrane or an indirect inhibition of active sodium transport as possible mechanisms.

Another area involving control of sodium reabsorption which has aroused some interest is the possibility of a circulating natriuretic hormone produced during volume expansion. This notion was first suggested by deWardener, et al. (30) on the basis of experiments in which dogs, treated with large amounts of mineralocorticoids and vasopressin, responded to saline infusion with a rise in urinary sodium excretion despite the deliberate depression of glomerular filtration rate. Whole sera and fractions of sera from such volume expanded animals were tested on rats with micropuncture techniques, and initially Rector, et al. (31) proposed that a hormone had been found which would inhibit sodium reabsorption when infused intravenously into a non-volume-expanded test animal or placed directly in the proximal tubular lumen. Other investigators using similar methods, however, have failed to duplicate these findings (32,33). The controversy over whether such a hormone exists or whether the effects of volume expansion on sodium reabsorption are entirely mediated by peritubular factors is still unsettled.

Other possible mechanisms of control of sodium reabsorption have been suggested. An attractive hypothesis defended by convincing experi- 
ments was set forth by Horster and Thurau (34). They demonstrated that in addition to mechanisms which regulate sodium reabsorption in different segments of the nephron, alterations in the function of different portions of the population of cortical nephrons could also exert a controlling influence. In this analysis, they distinguished two separate populations of cortical nephrons, superficial and juxtamedullary. By calculating single nephron glomerular filtration rates, they found that on a low sodium diet, individual superficial tubules had filtration rates that were less than one-half those of juxtamedullary tubules. However, when rats were maintained on extremely high sodium diets with saline for drinking water, the superficial, short-looped nephrons filtered fluid at greater than twice the rate of the juxtamedullary, long-looped group although there was only a minimal increase in the total kidney glomerular filtration rate. It was felt that by altering renal hemodynamics (possibly via the renin-angiotensin system), the organism was able to cope with states demanding sodium excretion on sodium retention by adjusting the distribution of flow to either the sodium wasting (superficial) on sodium retaining (juxtamedullary) nephrons. Therefore, without altering the inherent reabsorptive capacities of the proximal tubules, total kidney tubular reabsorption could be varied by the distribution of renal blood flow. This concept is supported by the finding that, in clinical states associated with sodium and fluid retention, superficial contical blood flow is depressed to a greater extent than is flow to the rest of the cortex and medulla (35).

The description of the events of sodium and water reabsorption at the cellular level has been approached with many different techniques by the morphologist, the histochemist, the electrophysiologist and the enzyme biochemist. Recent reviews have incorporated much of this data 

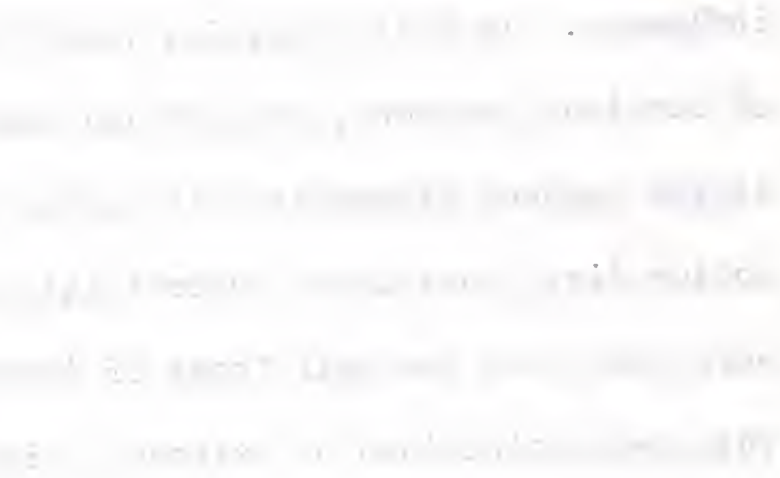
nons 
into a working model which has been the basis for the explanation of many experimental manipulations $(36,37,38)$. They describe a multicompartmental system in which the process of sodium reabsorption occurs as follows. Sodium ions cross the relatively permeable luminal membrane into the epithelial cell down an electrochemical gradient with water passively following out of the lumen by osmotic flow. These cations are then actively extruded into the basal labyrinth and the long intercellular channels. The latter are structures which are closed at the luminal end in tight junctions and widen to empty into the peritubular space. It has been shown that the bulk of demonstrable intracellular sodium and an enzyme system, sodium-potassium activated adenosine triphosphatase, are both associated with the membranes forming the structures described above $(39,40)$. This enzyme is one which has long been implicated in descriptions of the postulated sodium pump in many actively transporting epithelia, including the renal proximal tubule (41). More recent evidence suggests, however, that this enzyme may not be the only one involved in extrusion of intracellular sodium, but that another enzyme may be more effective in regulating cell volume by expelling sodium accompanied by chloride ions, and not requiring the exchange of potassium for activation (42). Once the sodium ions have been actively transported out of the epithelial cell, Diamond (43) postulates that the ions set up "standing osmotic gradients" which cause water to flow out of the cells into the basal labyrinth and down the intercellular channels to accompany the sodium and return the solutions to isotonicity by the time they reach the peritubular environment. It is felt that it is this constant extrusion of solute and water toward the peritubular space which may be sensitive to the physical forces of hydrostatic pressure and colloid oncotic pressure, discussed above. 

From this brief review it can be seen that many factors are known to exert some control over net sodium efflux in the proximal tubule. The relationships of these factors of filtration rate, hormones, tubular geometry, peritubular forces and functional heterogeneity of the nephron population to one another and to the minute-to-minute control of proximal tubular reabsorption are not well comprehended. Other aspects, involved in control of the active and passive phases of sodium transport at the cellular level, are appreciated but not well understood. The studies described in this presentation were performed in an attempt to evaluate the nature and influence of an aspect which has been largely neglected thusfar, the permeability of the luminal membrane. The experiments were designed to examine what effect alterations in this barrier would have on sodium transport. This change in permeability was mediated by amphotericin B, an agent which has been shown to be effective in increasing plasma membrane permeability in several in vitro systems.

The effect of amphotericin B.

Amphotericin B is a polyene antibiotic which was originally produced by the actinomycete, Streptomyces nodosus. It is the drug of choice for treatment of any deep-seated mycoses, but it has an unfortunately large number of toxicities, including reasonably frequent renal damage (44). This renal toxicity has been extensively investigated both clinically and experimentally, and it is felt that most of the damage is attributable to a vasoconstrictive effect of the antibiotic causing depression of perfusion and subsequent lowered glomerular filtration rate $(45,46)$. More recently, the pathological picture of nephrocalcinosis and the occurrence of hypokalemia and hyposthenuria occasionally preceeding azotemia was investigated by McCundy, et al. (47). They found that patients 


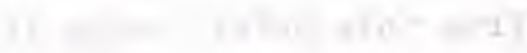

$+1$

$1,1,1$

\section{$+\mathrm{nE}^{-}$}

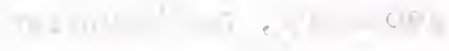

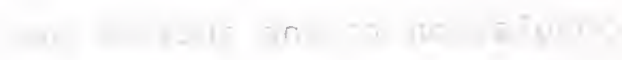

7

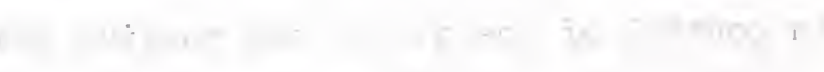

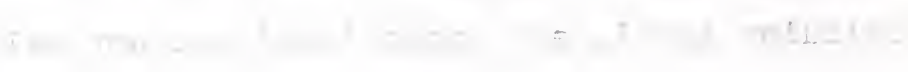

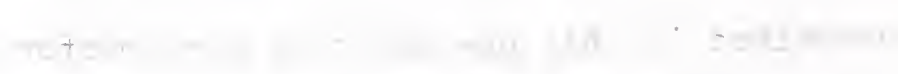

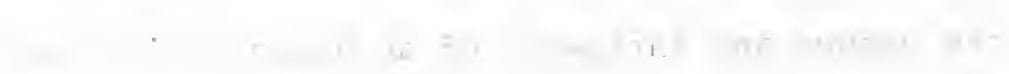

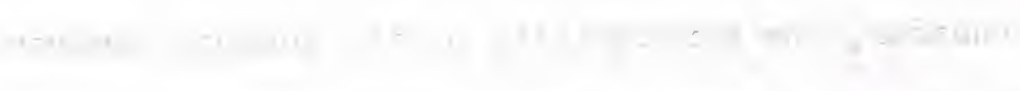

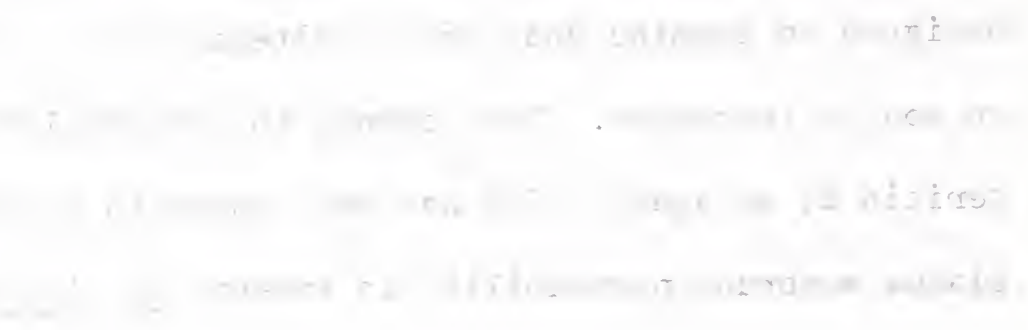

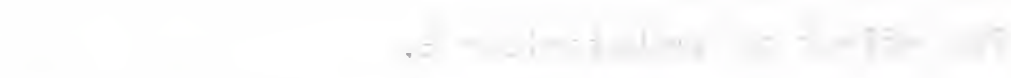

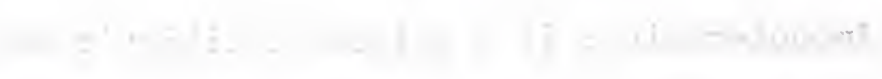

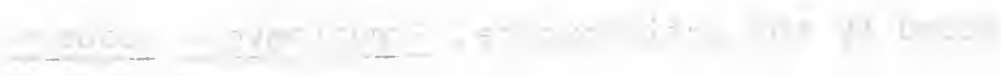

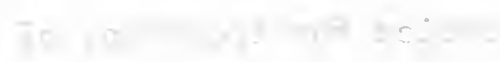
(2)

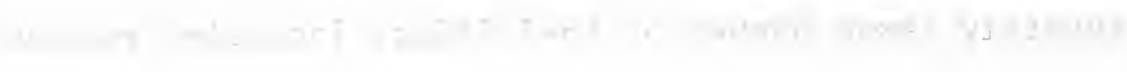

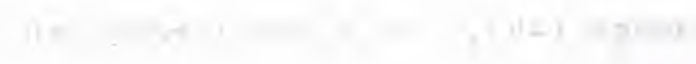

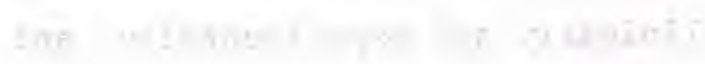

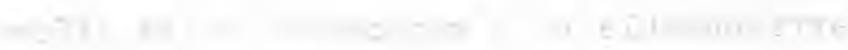

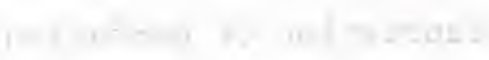

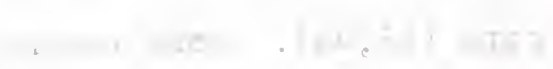


being treated with amphotericin B frequently demonstrated the clinical findings of distal renal tubular acidosis.

In the experiments described in this presentation, the dose of amphotericin B used was based on the work done with the toad uninary bladder by Lichtenstein and Leaf (48), who found maximal effects of amphotericin B at $13 \mathrm{\mu g} / \mathrm{ml}$. In an attempt to guarantee an effect in the perfused, intact, renal proximal tubule, the initial in vivo dose was increased to $50 \mathrm{\mu g} / \mathrm{ml}$, a level which did produce some effect. In their study, Lichtenstein and Leaf state that sodium desoxycholate, the solubilizing agent for amphotericin B, produced no significant effect in their preparation. It was felt that this agent should also be tested in a mammalian system. Consequently, following experiments on the first group of rats used both for learning of technique and acquiring control data, the effects of intratubular injections of two experimental substances, amphotericin B and desoxycholate, were evaluated.

The action of amphotericin $B$ was assessed under stop-flow conditions to diminish the influence of possible systemic effects of this agent. Therefore, the changes occurring with intratubular application of this drug can probably be attributed to its local activity. From Table 2, it can be seen that when amphotericin B was added to the tubular lumen,

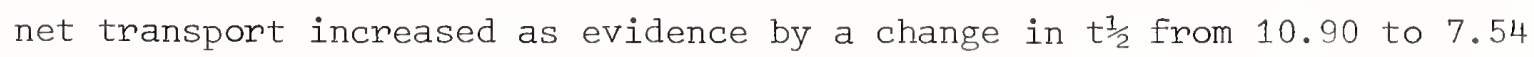
seconds, a significant decrease of greater than $30 \%$. When expressed as net water flux, an increase in magnitude from $-5.67 \times 10^{-4} \mathrm{~mm}^{3} / \mathrm{mm}^{2}$ per second to $-8.19 \times 10^{-4} \mathrm{~mm}^{3} / \mathrm{mm}^{2}$ per second was demonstrated. There is also an apparent decrease in $t^{\frac{1}{2}}$ from control values associated with desoxycholate, although amphotericin B produced a further significant decrease in $t \frac{1}{2}$ of approximately $20 \%$ from the desoxycholate value. The difference between the saline control and desoxycholate may, in fact, be influenced by the improvement in technical ability of the novice 

investigator, and its significance is therefore subject to question. In summary, there is evidence that by the action of amphotericin B on the luminal membrane of the proximal tubular epithelium, this drug increased sodium and fluid reabsorption in an isolated segment of mammalian proximal tubule.

The results in this mammalian system were duplicated and elaborated upon in experimentation with the proximal tubule of Necturus (49). Stroup and Kashgarian have found that at concentrations of both $10 \mu \mathrm{g} / \mathrm{ml}$ and 50 $\mu \mathrm{g} / \mathrm{ml}$, amphotericin $\mathrm{B}$ reduced the $t \frac{1}{2}$ to approximately $50 \%$ of control values. It was also found that solute influx into an intraluminal, isotonic raffinose droplet was significantly increased by amphotericin $B$. Finally, in measuring equilibrium concentrations, they found that the concentration of sodium was unchanged but that of potassium was distinctly increased. They interpreted this data as an effect of amphotericin B causing increased passive permeability and depolarization of the luminal membrane which was associated with increased net transport of solute and water.

The only other work with this agent in altering membrane permeability has been in in vitro systems, particularly the toad bladder. Lichtenstein and Leaf (48) originally used amphotericin B with vasopressin to demonstrate the double series permeability barrier originally postulated by Andersen and Ussing (50) in the toad skin. The membrane, according to this concept, consists of an outer homogeneous diffusion barrier with low permeability to most hydrophilic solutes and a deeper porous barrier which resists bulk water flow, the latter being particularly sensitive to amphotericin B in Lichtenstein and Leaf's experiments. Their results were challenged by Mendoza, et al. (51), using similar techniques, who found that the effect of amphotericin B on the toad bladder was not limited to 

only one of the barriers. They cautioned that the assumption that amphotericin $B$ acts only at a single site was not proven, and that the actions of other agents should not be interpreted on this basis. Finn (52), also using the toad bladder, determined that amphotericin B was active at both serosal and mucosal membranes, causing increased passive movement of sodium ions across the membrane facing the medium to which amphotericin $B$ had been added. Singer, et al. (53) have evaluated many of the variables affecting the toad bladder preparation including season of the year, time after dissection, initial short-circuit current and initial potential difference across the membrane. They found that under certain conditions, the original observations of Lichtenstein and Leaf (48) could be consistently reproduced and reaffirmed the double barrier membrane hypothesis. The effects of amphotericin B on the toad bladder were elegantly studied by Saladino, et al. (54), who correlated the electrophysiological and ultrastructural changes in mucosal cells during exposure to this agent over various periods of time. They found that amphotericin $B$ reduced the capacity of apical plasma membranes to maintain intracellular gradients. After a few hours of incubation with the antibiotic, structural and functional disintegration occurred, with intracellular swelling and mitochondrial matrix condensation. Ultimately, there was necrosis with swelling of intracellular ground substance and disruption of many organelles. In the early phases, at two and eight minutes, before demonstrable morphological cell disruption could be demonstrated, there was a persistent increase in short-circuit current implying increased transport by a still competent, unsaturated sodium pump. This parameter fell in concordance with the demonstrated breakdown of cellular integrity during more prolonged incubations.

Other in vitro systems have been examined with amphotericin B. 


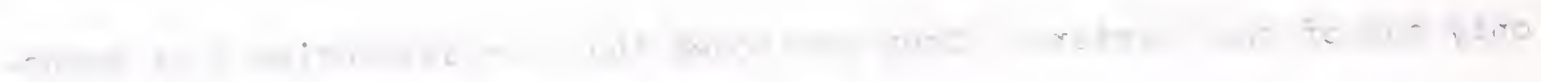
-

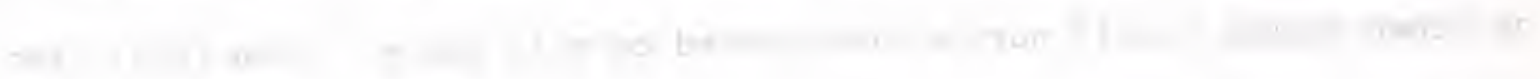

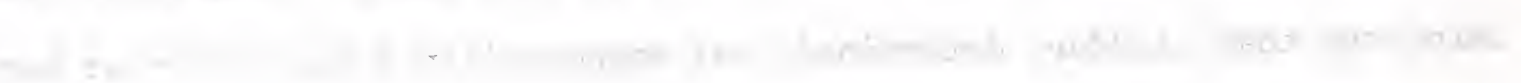

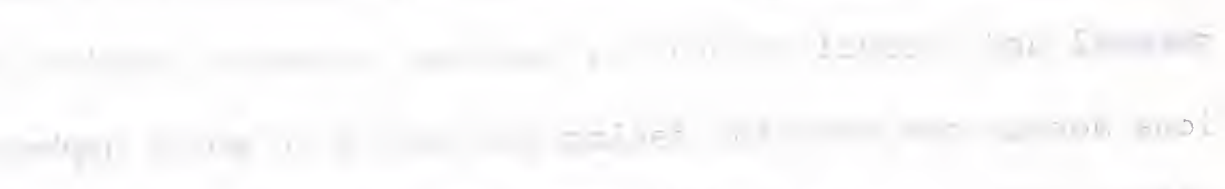

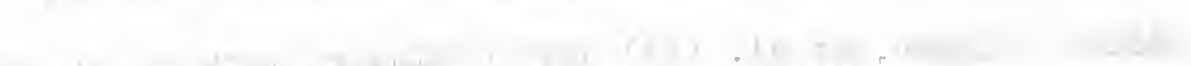

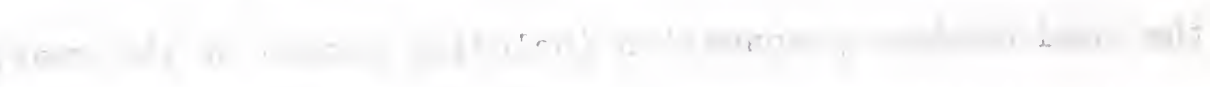
.

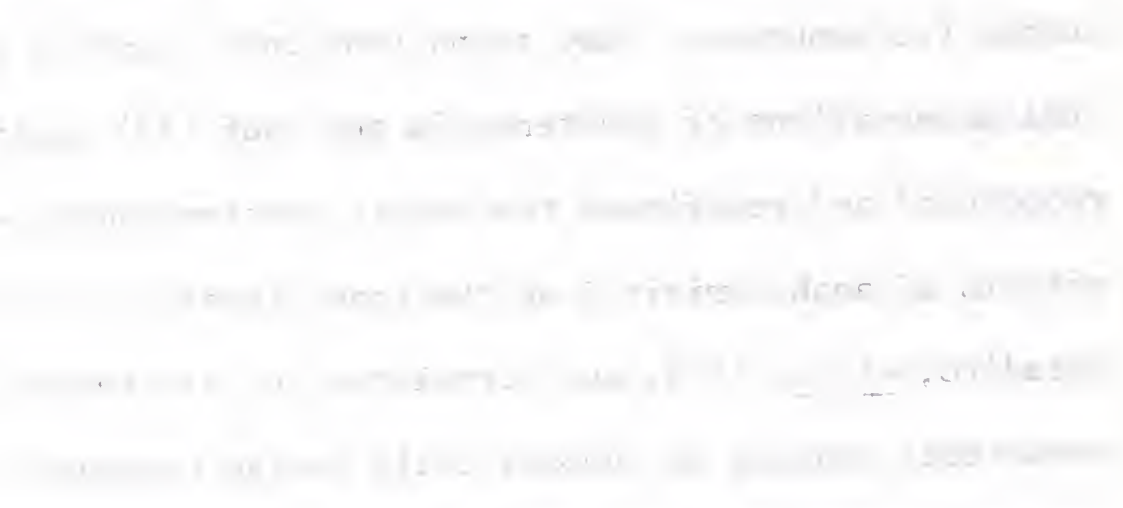

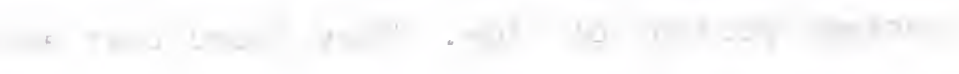

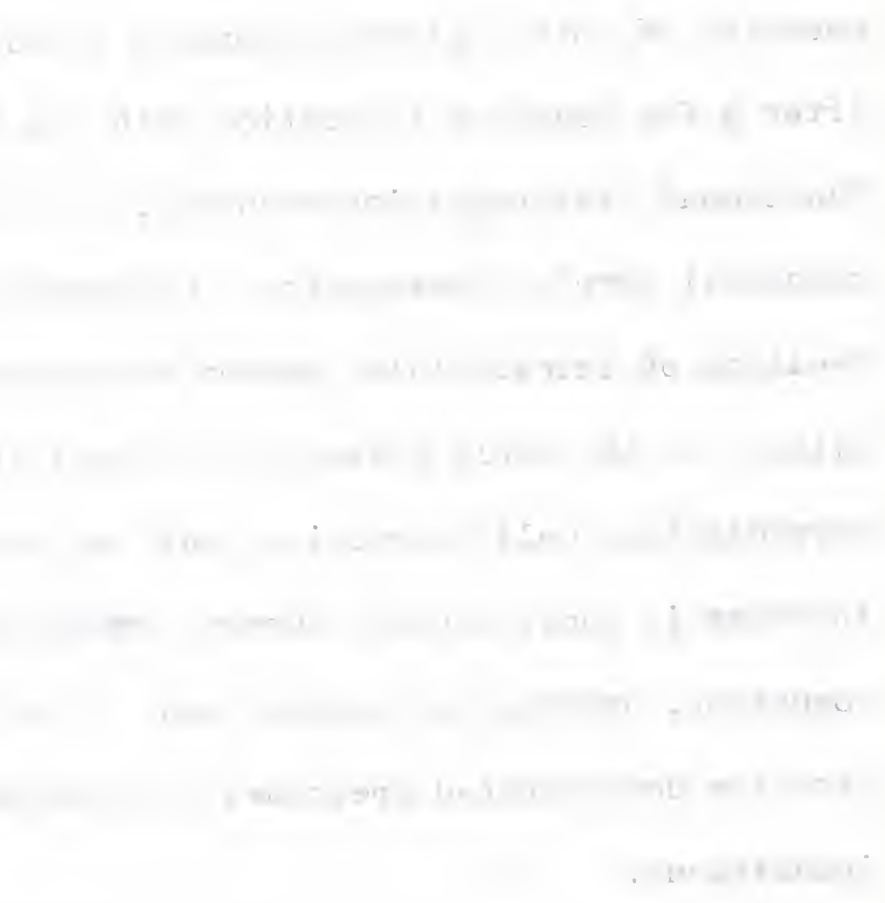


Lippe and Giondana (55) exposed the small and large intestines of the tortoise to various concentrations of amphotericin B and found that at the same dosage of drug, permeability to thiourea was increased far more in the large intestine. They also noted that permeability changes seemed to affect the transport of smaller molecules much more than that of molecules which were the size of creatinine or larger, and that there was no change in the permeability to lipid soluble molecules. Steinmetz and Lawson (56) found that in the turtle bladder, amphotericin B caused a defect in urinary acidification due to increased passive permeability of the luminal membrane resulting in increased back diffusion of hydrogen ion. It was also shown that there were langer increases in permeability to potassium than to sodium and chloride, and the authors suggested that this model might be analogous to the clinically described renal tubular acidosis found in some patients being treated with amphotericin B (47). These in vitro studies generally tend to support a consistent action of amphotericin $B$ of increasing the passive permeability of most membranes facing media containing this drug, rather than any direct influence on active transport in the system being examined.

The mode of action of this agent in altering membrane permeability has been studied for several years. The susceptibility of fungi, but not bacteria, to the polyene type of antibiotic suggested that some difference in the composition of the plasma membrane was the basis of differential sensitivity to these drugs. Working with nystatin, a polyene with a mode of action similar to that of amphotericin B, and fungal protoplasts, Lampen, et al. (57) suggested that antibiotic binding by the plasma membrane was the critical event in cell damage and that the binding site contained sterols, types of lipids which are not found in bacteria. Furthermore, studies comparing mammalian erythrocytes with fungal protoplasts demonstrated that, at low concentrations of polyenes, there was a rapid lysis 


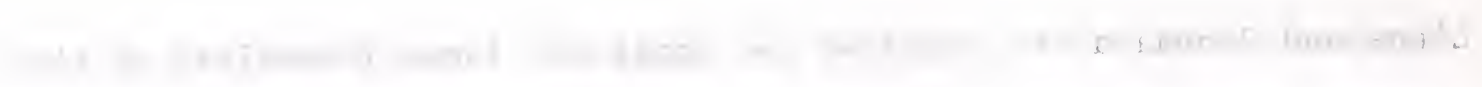

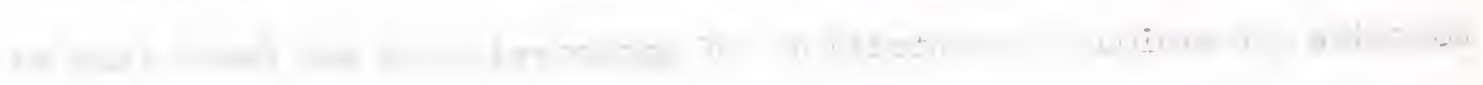

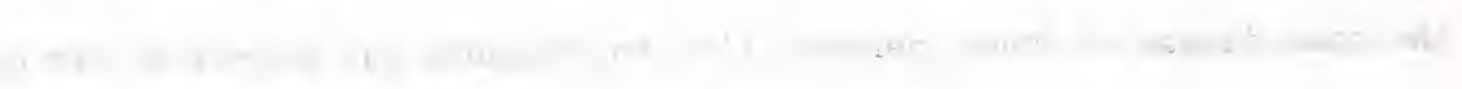
r.t. (1)

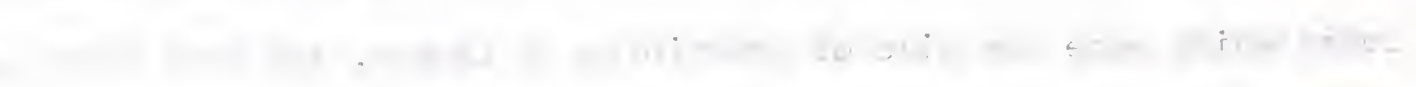

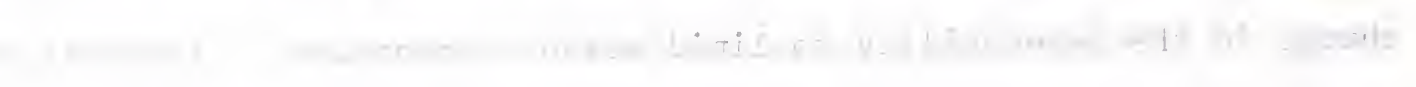

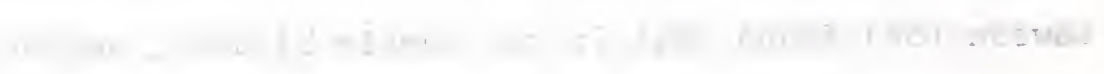

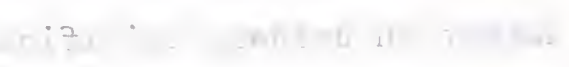

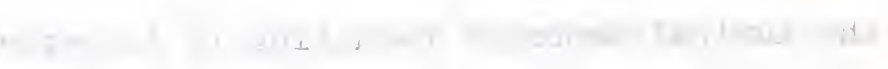
HL

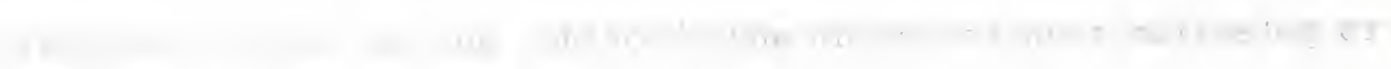

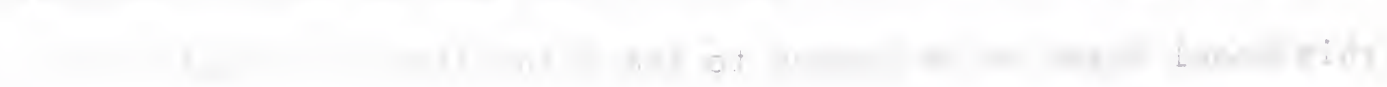

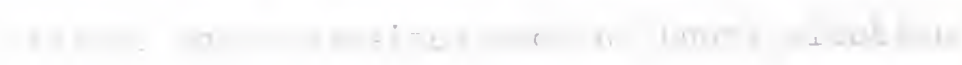

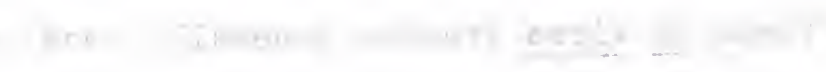

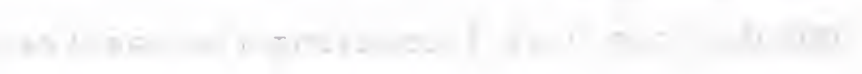

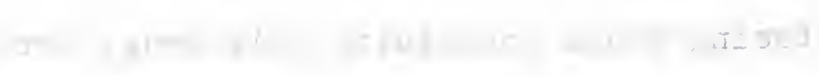

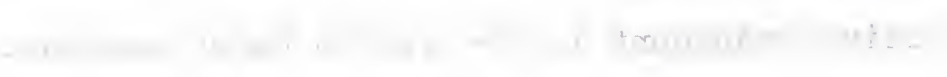

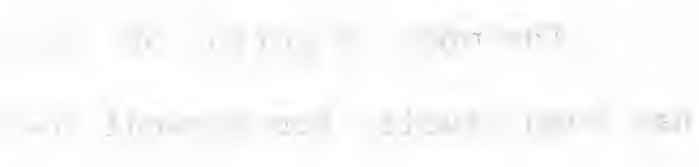

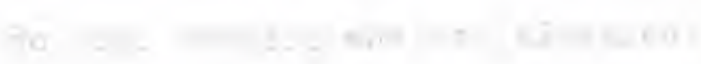

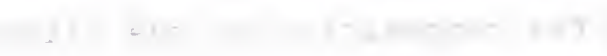


of both types of cells, indicating that mammalian membranes, too, were susceptible to these drugs and that the induced changes caused greatly increased membrane permeability (58). Using the physical chemical concept of "lipid monolayer penetration", Demel and his associates (59) found that the sterol moiety, rather than the phospholipid component, of plasma membranes was most sensitive to the amphotericin B and proposed that the mode of action was one of "reorientation" of the sterols in membranes leading to increased permeability and leakage of intracellular components. More recent work has indicated that the maximal effect of amphotericin B on artificial phospholipid-cholesterol structures was found in certain combinations of phospholipid and sterol, rather than in pure cholesterol monolayers $(60,61)$. These findings, regarding both real plasma membranes and Iipid analogues, indicate that some sort of binding of polyene to sterol occurs, leading to a reorientation of the sterol molecules, resulting in increased permeability of the involved membrane. The binding aspect of this concept is further supported by the finding of Mendoza, et al. (51) that ergosterol inhibits the action of amphotericin B in the toad bladder preparation, presumably by competing with membrane binding sites for the free antibiotic.

In light of the findings of the many workers who used amphotericin $B$ in in vitro or chemical systems, some explanation can be put forth for the increased reabsorption in the mammalian proximal tubule which has been exposed to this agent. It appears that amphotericin B, from the intratubular tubular perfusate bathing the luminal membrane, interacted with this mammalian, sterol-containing membrane for a short period of time and caused increased permeability without intracellular disruption. With this relative barrier to solute penetration somewhat attenuated, increased ionic sodium and water crossed into the cell. Since larger 
amounts of sodium were presented to the sodium pump, this mechanism was able to move the sodium out of the cell at a rate which was more rapid than normal. Whether this altered capacity for ionic transport was due to lack of substrate saturation under control conditions or, possible, to increased ability of an already saturated pump, is subject to question. The results of Stroup and Kashgarian (49) of unchanged equilibrium concentration of intratubular sodium during amphotericin B exposure, indicate that active transport is unchanged in the amphibian kidney. Furthermore, the findings of Sharp and his associates (62) in the toad bladder, demonstrate that the increased active transport of sodium due to incubation of the tissue in aldosterone is augmented by treatment with amphotericin B. This finding can be interpreted as an indication that a more potent active transport system can be even further responsive to an increase in substrate level, if that level remains below the saturation limit of the pump.

The experimental results and this formulation suggest that crossing the luminal membrane is a rate limiting step in net sodium outflux. Therefore, altering the permeability characteristics of this barrier may be an important mechanism in regulating sodium movement across the proximal tubule, independent of filtration rate, hormones, physical factors and other postulated influences on sodium transport. The practical importance of the ability to manipulate this barrier is that it should be considered a potentially dynamic structure, possibly capable of both response to and control of altered conditions of solute transport, rather than a non-variable portal for delivery solute to the pump.

The Split-Droplet Method

The method used in these experiments was the split-droplet technique, 

originally developed by Gertz (5). It is an attempt to measure the intrinsic reabsorptive capacities of the proximal and distal tubules, independent of the effect of filtration rate, and it also affords an opportunity to manipulate the composition of the perfusate in order to locally, rather than systemically, affect the reabsorptive apparatus. In many studies where both free-flow and stop-flow micropuncture techniques were employed under the same experimental conditions, there has been excellent correspondence between the results of the two methods $(4,6,24,29)$. Several investigators, however, have recently questioned the reliability of this method, and, therefore, attempts were made to control many of the variables in the experimental technique. The initial droplet length was standardized, the oil block was adequate to prevent flow but not excessively long, and observer bias was limited by the measurement of coded photographs and the statistical regression approach to $t^{\frac{1}{2}}$ calculation. The considerations to be described are included to explain the reasons why standardization of these variables may be crucial to the reproducibility and reliability of this method.

In the presentation of the results of this experimentation, it was indicated that certain limits were set on the initial length of the droplet. The rationale behind such setting of limits is, in part, based on the realities of droplet geometry. The concept of considering the intermeniscal length to be proportional to volume is based on the assumption that the droplet shape approaches a regular cylinder with plane bases. From the pictures of the reabsorption sequence (Fig. 1), it is obvious that this is an oversimplification. In the photographs, the menisci appear to approximate semicircles; these would be equivalent to hemispheres of oil in three dimensions since the radius of the tubule is felt to remain constant. An expression for the actual volume of the droplet can be 

derived based upon this description of the shape of the meniscus (Fig. 4). The actual volume $(v)$ is equal to the volume of a cylinder, with length equal to the intermeniscal length (I) plus the radii of both hemispheres $(2 r)$, minus the volume occupied by the two hemispheres:

(8) $v=\pi r^{2}(1+2 r)-2 \cdot 2 / 3 \pi r^{3}-\pi r^{2}(L=2 / 3 r)$.

It can be readily seen, therefore, that as an approximation of volume, $\pi r^{2} 1$ becomes a smaller proportion of the actual droplet volume as 1 decreases, approaching $r$. Steinhausen (63) originally described this phenomenon, noting that at initial lengths less than $90 \mu$, a distance approximately equal to five tubular radii (5r), there was a definite correlation between initial length and $t \frac{1}{2}$. In recent experiments performed in this laboratory, a lower limit of initial length equal to $4 \mathrm{r}$ has been set for acceptable droplets. This is based on Weinman's (64) finding that a plot of initial length against $t^{\frac{1}{2}}$ disclosed a region from $60 \mu$ to $90 \mu$ (approximately $4 \mathrm{r}$ to $6 \mathrm{r}$ ) over which there was no significant conrelation between these variables, but, above and below these limits, there seemed to be an effect of initial droplet length on calculated reabsorption. If these criteria had been used for the data in these experiments, too small a sample size would have resulted, and I therefore, compromised

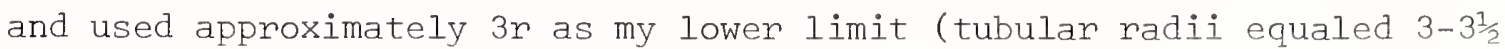
units). This value was consistent with the minimal droplet length criterion of approximately $2^{\frac{1}{2}} \mathrm{r}$ originally established by Nakajima, et al. (65) in canine proximal tubules. It was, however, far short of the $100 \mu$ minimum (approximately 7r) recently used by Bank's group (66).

The upper limit of 20 units is approximately $6 \mathrm{r}$ which was consistent with limits suggested by Weinman (64), and it provided an overall range of 3-6r which produced a control distribution of $t \frac{1}{2}$ that was sufficiently random between the limits so that there was no significant correlation 
37 Figure 4 Approximation of actual
droplet volume.

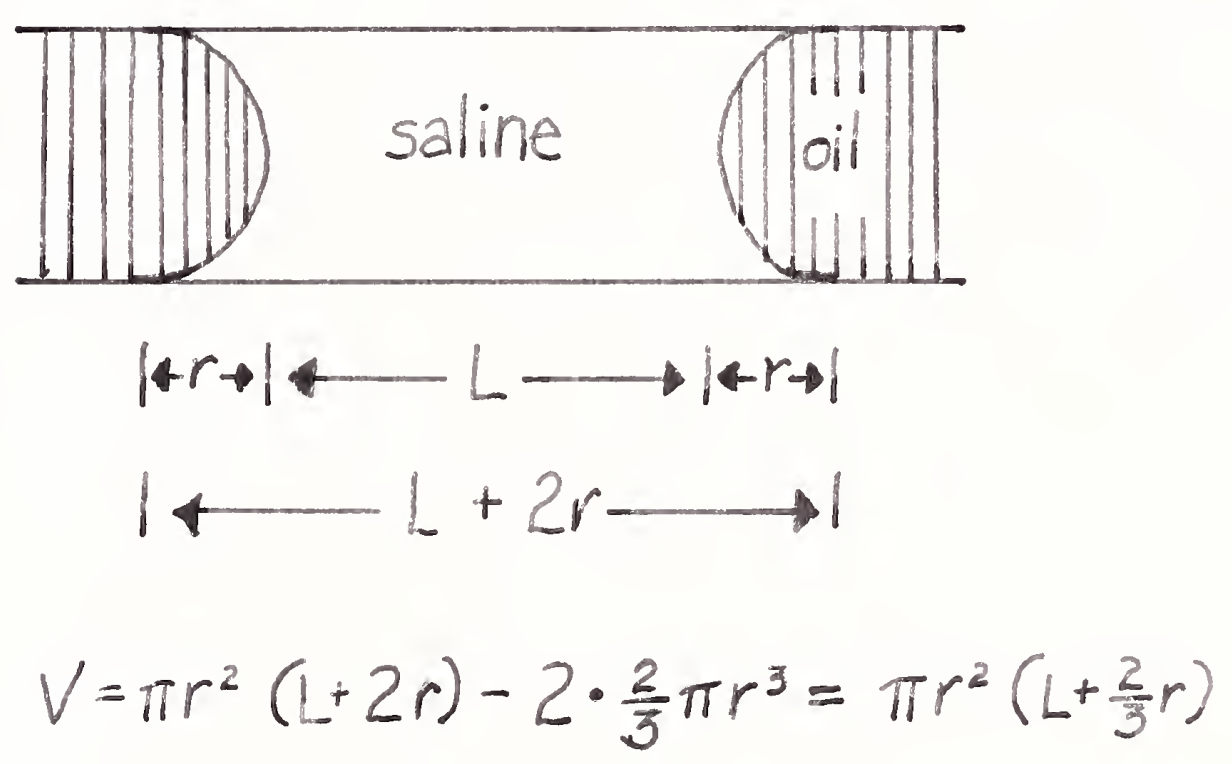




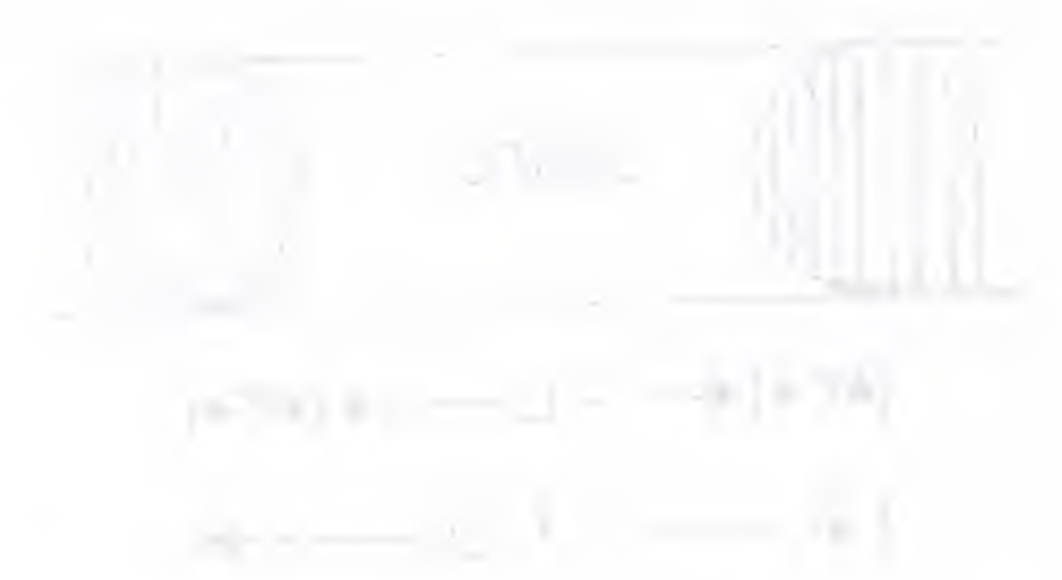


with initial length (Fig. 3). Furthermore, even if one accepted the claim of Levinsky, et al. (67) that in their hands, there is no range within which $t \frac{1}{2}$ is not affected by initial length, my setting of limits within which there were reasonably similan distributions of initial lengths for all experimental groups would tend to control for this effect.

There have recently been other criticisms of the split-droplet technique and attempts to revise it by altering methods of measurement, calculation and the injection of the intratubular oil block. Many techniques have been devised for measuring the lengths of droplets which may not be totally straight. Among these are the projection of colored transparencies or black and white negatives of photographs of droplets, with the intermeniscal distances determined by several means. These include the use of planimeters or mapreaders $(28,31)$, paper cut-outs of the outlines of tubules with the estimation of the percent decrease in volume based on weight change (29), and division of the projected droplets into roughly rectangular midplane, cross sectional areas with the summation of these areas as the representation of tubular volume (68). Bentzel, et al. (69) have used formula (8), with direct measurements of intermeniscal length and tubular diameter to better approximate actual tubular volume.

To calculate $t \frac{1}{2}$, all of these methods involve a semilogarithmic plotting of percent change in the parameter representing volume against time, with a best-fit line drawn by eye. In the experience in this laboratory, attempts to draw this line have often been complicated by the lack of colinearity of all points and decisions were made whether to neglect the aberrant point(s) on to try to adjust the best-fit line. For these experiments, in order to give adequate consideration to all data collected on each droplet, the changes in intermeniscal distance were calculated into a statistical regression. In this computation, the 

slope of each point from the initial point was weighted equally, thus eliminating another possible source of observer bias.

Most investigators continue to calculate $t \frac{1}{2}$ based on some parameter representative of tubular volume. In their study, Nakajima, et al. (65), concluded that the factor actually being varied in the split-droplet technique was the reabsorptive surface area exposed to the droplet. In recalculating their data, they found no effect of initial length on $t^{\frac{1}{2}}$, if the regression of the total length of tubule exposed to the droplet (including the area behind each meniscus) was calculated. Although this was not Gertz's $(4,5)$ original formulation, it may well be that their rationale, which seemed to evolve from a mathematical manipulation performed to eliminate the influence of initial length on $t \frac{1}{2}$, is correct.

Some attention has recently been paid to the nature of the oil block. Levinsky, et al. (67) found that the length of the distal oil block had no effect on control studies, but, after volume expansion, the large oil block was associated with much less of an increase in $t \frac{1}{2}$ than the smaller block. Nakajima, et al. (65) found a difference in $t^{\frac{1}{2}}$ when the composition of the oil was altered and also raised the possibility that there were different frictional resistances to movement affecting the proximal and distal oil blocks. Finally, they suggested that there might be adverse effects of the oil on reabsorption. This criticism can be refuted in part, by the correlation of ultrastructural and physiological observations on the effect of oil on the reabsorptive epithelium performed by wiederholt and his associates (70). They demonstrated that contact with castor oil and tubular dilatation with the oil block do not damage the epithelium to any measurable degree, as judged morphologically and functionally, even after several applications of the technique to the same segment. 

It can be seen that there are several possibilities for introducing methodological artifacts into the assessment of reabsorption by the split-droplet technique. I believe, however, that the limitations placed on this basically reliable method in these experiments have permitted the generation of data which represent actual physiological alterations and demonstrate a real effect of amphotericin $B$ on the mammalian proximal tubule. 



\section{SUMMARY}

The effect of the intratubular injection of amphotericin B on proximal tubular reabsorption was examined using the split-droplet micropuncture method. Under these conditions, reabsorptive half-time was significantly decreased, indicating an increase in the rate of proximal tubular reabsorption. This was interpreted as being due to a more permeable luminal membrane allowing increase passive efflux of sodium and water. These studies implied that the luminal membrane was a rate limiting barrier in proximal tubular sodium reabsorption. 



\section{REFERENCES}

1. Wirz, H. Druckmessung in Kapillaren und Tubuli der Niere durch Mikropunkture. Helvet. Physiol. et Pharmacol. Acta, 13: $42,1955$.

2. Steinhausen, M. Eine Methode zur Differenzierung proximaler und distaler Tubuli der Nierenrinde von Ratten in vivo und ihre Anwendung zur Bestimung tubulärer Strömungsgeschwindigkeiten. Pflügers Arch. ges. Physiol., 277: 23, 1963.

3. Gottschalk, C. W. and Mylle, M. Micropuncture study of pressures in proximal tubules and peritubular capillaries of the rat kidney and their relations to ureteral and renal venous pressure. Am. J. Physiol., 185: 430, 1956.

4. Gertz, K. H., Mangos, J. A., Braun, G. and Pagel, H. D. On the glomerular tubular balance in the rat kidney. Pflügers Arch. ges. Physiol., 285: 360, 1965.

5. Gertz, K. H. Transtubuläre Natriumchloridflússe und Permeabilität für Nichtelektrolyte im proximalen und distalen Konvolut der Rattenniere. Pflügers Arch. ges. Physiol., 276: 336, 1963.

6. Hayslett, J. P., Kashgarian, M. and Epstein, F. H. Functional correlates of compensatory renal hypertrophy. J. Clin. Invest., 47: $774,1968$.

7. Walker, A. M., Bott, P. A., Oliver, J. and MacDowell, M. Collection and analysis of fluid from single nephrons of the mammalian kidney. Am. J. Physiol., 134: 580, 1941.

8. Ullrich, K. J., Schmidt-Nielsen, B., O'Dell, R., Pehling, G., Gottschalk, C. W., Lassiter, W. E. and Mylle, M. Micropuncture study of proximal and distal tubular fluid in rat kidney. Am. I. Physiol., 204: 527, 1963. 

9. Clapp, J.R., Watson, J.F. and Berliner, R. Osmolality, bicarbonate concentration, and water reabsorption in proximal tubule of the dog nephron. Am. J. Physiol., 205: 273, 1963.

10. Windhager, E. E. and Giebisch, G. Micropuncture study of renal tubular transfer of sodium chloride in the rat. Am. J. Physiol., 200: 581, 1961.

11. Kashgarian, M., Stöckle, H., Gottschalk, C. W. and Ullrich, K. J. Transtubular electrochemical potentials of sodium and chloride in proximal and distal renal tubules of rats during antidiuresis and water diuresis (diabetes insipidus). Pflügers Arch. ges. Physiol., 277: 89, 1963.

12. Kiil, F., Aukland, K. and Refsum, H. E. Renal sodium transport and oxygen consumption. Am. J. Physiol., 201: 511, 1961.

13. Deetjen, P. and Kramer, K. Reabsorption and oxygen consumption in the mammalian kidney. Klin. Wchschnr., 38: 680, 1960.

14. Lindheimer, M. D., Lalone, R. C. and Levisky, N. G. Evidence that acute increase in glomerular filtration has little effect on sodium excretion in the dog unless extracellular volume is expanded. J. Clin. Invest., 46: 256, 1967.

15. Smith, H. W. The Kidney: Structure and Function in Health and Disease, P. 460, New York, 1951. Oxford University Press.

16. Dirks, J. H., Cirksena, W. J. and Berliner, R. W. Effects of saline infusion on sodium reabsorption by proximal tubule of dog. J. Clin. Invest., 44: 1160, 1965.

17. Brenner, B. M., Bennet, C. M. and Berliner, R. W. Relationship between glomerular filtration rate and sodium reabsorption by proximal tubule of rat kidney. J. Clin. Invest., 47: 1358, 1968. 

18. Morgan, T. and Berliner, R. W. In vivo perfusion of proximal tubules of the rat: Glomerulotubular balance. Am. I. Physiol., 217: 992, 1969 .

19. Mills, J. N., Thomas, S. and Williamson, K. S. Effects of intravenous aldosterone and hydrocortisone on urinary electrolytes of the recumbent human subject. I. Physiol., 156: 415, 1961.

20. Hierholzer, K., Wiederholt, M. and Stolte, H. Hemmung der Natriumresorption im proximalen und distalen Konvolut adrenalektomierter Ratten. Pflügers Arch. ges. Physiol., 291: 43, 1966.

21. Wiederholt, M., Stolte, H., Brecht, J. P. and Hierholzer, K. Mikropunktionsuntersuchunger uber den Einfluss von Aldosteron, Cortison und Dexamethason auf die renale Natrium resportion adrenalektomierter Ratten. Pflügers Arch. ges. Physiol., 292: 316, 1966.

22. Rector, F. C., Jr., Brunner, F. B. and Seldin, D. W. Mechanism of glomerulotubular balance. II. Regulation of proximal tubular reabsorption by tubular volume as studied by stopped-flow microperfusion. I. Clin. Invest., 45: 603, 1966.

23. Schnermann, J., Wahl, M., Liebau, B. and Eishbach, H. Balance between tubular flow rate and net fluid reabsorption in the proximal tubule of the rat kidney. I. Dependency of reabsorptive net fluid flux upon proximal tubular surface area at spontaneous variations of filtration rate. Pflugers Arch. ges. Physiol., 304: 90, 1968.

24. Lewy, J. E. and Windhager, E. E. Peritubular control of proximal tubular fluid reabsorption in the kidney. Am. I. Physiol., 214: $943,1968$. 

25. Earley, L. E. and Friedler, R. M. The effects of combined renal vasodilatation and pressor agents on renal hemodynamics and the tubular reabsorption of sodium. J. Clin. Invest., 45: 542, 1966.

26. Earley, L. E., Martino, J.A. and Friedler, R. M. Factors affecting sodium reabsorption by the proximal tubule as determined during blockade of distal sodium reabsorption. J. Clin. Invest., 45: $1668,1966$.

27. Martino, J. A. and Earley, L. E. Demonstration of a role of physical factors as determinants of the natriuretic response to volume expansion. J. Clin. Invest., 46: 1963, 1967.

28. Koch, K. M., Aynedjian, H. S. and Bank, N. The effect of acute hypertension on sodium reabsorption by the proximal tubule. J. Clin. Invest., 47: 1696, 1968.

29. Spitzer, A. and Windhager, E.E. Effect of peritubular oncotic pressure changes on proximal tubular fluid absorption. Am. J. Physiol., 218: 1188, 1970.

30. deWardener, H. E., Mills, I. H., Clapham, W. F. and Hayter, C. J. Studies on efferent mechanism of sodium diuresis which follows administration of intravenous saline in dog. Clin. Sci., 21: $249,1961$.

31. Rector, F. C., Jr., Martinez-Maldonado, M., Kurtzman, J. C., Oerther, F. and Seldin, D. W. Demonstration of a hormonal inhibitor of proximal tubular reabsorption during expansion of extracellular volume with isotonic saline. J. Clin. Invest., 47: 761, 1968. 32. Wright, F. S., Brenner, B. M., Bennet, C. M., Keimowitz, R. I., Berliner, R. W., Schrier, R. W., Verroust, P. J., deWardener, H. E. and Holzgreve, H. Failure to demonstrate an hormonal inhibitor of proximal sodium reabsorption. J. Clin. Invest., 48: 1108, 1969. 

33. Hayslett, J. P., Weinstein, E., Kashgarian, M. and Epstein, F. H. Attempts to demonstrate a hormonal natriuretic factor by micropuncture techniques. Yale J. Bio. Med., 41: 415, 1969.

34. Horster, M. and Thurau, K. Micropuncture studies on the filtration rate of single superficial and juxtamedullary glomeruli in the rat kidney. Pflügers Arch. ges. Physiol., 301: 162, 1968.

35. Barger, A. C. Renal hemodynamic factors in congestive heart failure. Ann. N.Y. Acad. Sci., 139: 276, 1966.

36. deWardener, H. E. Control of sodium reabsorption. Brit. Med. I., 3: $611,1969$.

37. Davis, B. B., Ir. and Knox, F. G. Current concepts of the regulation of urinary sodium excretion. Am. J. Med. Sci., 259: 373, 1970.

38. Giebisch, G. Functional organization of proximal and distal tubular electrolyte transport. Nephron, 6: 260, 1969.

39. Tisher, C. C., Cirksena, W. J., Arstila, A. U. and Trump, B. F. Subcellular localization of sodium in normal and injured proximal tubules of rat kidneys. Am. I. Path., 57: 231, 1969.

40. Ericsson, J. L. E. Electron microscopy of the normal tubule. In: Proc. Third Inter. Cong. Nephrol., Vol. 2, p. 1. Basel, New York, 1967. S. Karger.

41. Katz, A. I. and Epstein, F. H. Physiologic role of sodium-potassium activated adenosine triphosphatase in the transport of cations across biological membranes. New Eng. J. Med., 278: 253, 1967.

42. Proverbio, F., Robinson, J. W. L. and Whittembury, G. Sensitivities of $\left(\mathrm{Na}^{+}-\mathrm{K}^{+}\right)$-ATPase and sodium extrusion mechanisms to ouabain and ethacrynic acid in the contex of guinea pig kidney. Biochim. Biophys. Acta, 211: 327, 1970. 

43. Diamond, J. M. and Bossert, W. H. Standing gradient osmotic flow. A mechanism for coupling water and solute transport in epithelia. J. Gen. Physiol., 50: 2061, 1967.

44. Goodman, L. S. and Gilman, A. The Pharmacological Basis of Therapeutics, p. 1300, New York, 1970. MacMillan Co.

45. Bell, N. H., Andriole, V. T., Sebesin, S. M. and Utz, J. P. On the nephrotoxicity of amphotericin B in man. Am. J. Med., 33: $64,1962$.

46. Butler, W. T., Hill, G. J., II, Szwed, C. F. and Knight, V. Amphotericin B renal toxicity in the dog. J. Pharm. Exp. Therap., $143: 47,1964$.

47. McCurdy, D. K., Frederic, M. and Elkington, J. R. Renal tubular acidosis due to amphotericin B. New Eng. J. Med., 278: 124, 1968.

48. Lichtenstein, N. S. and Leaf, A. Effect of amphotericin B on the permeability of the toad bladder. J. Clin. Invest., 44: 1328, 1965.

49. Stroup, R. F. and Kashgarian, M. (Unpublished observations.)

50. Andersen, B. and Ussing, H. H. Solvent drag on non-electrolytes during osmotic flow through isolated toad skin and its response to ADH. Acta Physiol. Scand., 39: 228, 1957.

51. Mendoza, S. A., Handler, J. S. and Orloff, J. Effect of amphotericin $B$ on permeability and short-circuit current in toad bladder. Am. I. Physiol., 213: 1263, 1967.

52. Finn, A. L. Separate effects of sodium and vasopressin on the sodium pump in the toad bladder. Am. J. Physiol., 215: 849, 1968.

53. Singer, I., Civan, M. M., Baddow, R. F. and Leaf, A. Interactions of amphotericin B, vasopressin, and calcium in toad urinary bladder. Am. J. Physiol., 217: 938, 1969. 

54. Saladino, A. J., Bentley, P. J. and Trump, B. F. Ion movements in cell injury: Effect of amphotericin B on the ultrastructure and function of the epithelial cells of the toad bladder. Am. J. Path. , 54: 421, 1969.

55. Lippe, C. and Giordana, B. Effects of amphotericin B on the permeability of the small and large intestines of Testudo hermanii. Biochim. Biophys. Acta, 135: 966, 1967.

56. Steinmetz, P. R. and Lawson, L. R. Defect in urinary acidification induced in vitro by amphotericin B. J. Clin. Invest., 49: 596, 1970.

57. Lampen, J. O., Arnow, P. M., Borowska, Z. and Laskin, A. I. Location and role of sterol at nystatin binding sites. J. Bact. 84: 1152, 1962.

58. Kinsky, S. C. Comparative responses of mammalian erythrocytes and microbial protoplasts to polyene antiobiotics and vitamin A. Arch. Biochem. Biophys., 102: 180, 1963.

59. Demel, R. A., van Deenen, L. L. M. and Kinsky, S. C. Penetration of lipid monolayers by polyene antibiotics. Correlations with selective toxicity and mode of action. J. Biol. Chem., 240: 2749, 1965.

60. Weissman, G. and Sessa, G. The action of polyene antibiotics on phospholipid-cholesterol structures. I. Biol. Chem., 242: 616, 1967.

61. Demel, R. A., Crombag, F. J. L., van Deenen, L. L. M., Kinsky, S. C. Interaction of polyene antibiotics with single and mixed lipid monomolecular layers. Biochim. Biophys. Acta, 150: 1, 1968. 

62. Sharp, W. G., Coggins, C. H., Lichtenstein, N. S. and Jeaf, A. Evidence for a mucosal effect of aldosterone in sodium transport in the toad bladder. J. Clin. Invest., 45: 1640, 1966.

63. Steinhausen, M. Messungen des tubularen Harnstromes und der tubularen Reabsorption unter erhöhtern Ureterdruck (Intravita1mikroskopische Untersuchungen an der Nierenrinde von Ratten). Pflügers Arch. ges. Physiol., 296: 105, 1967.

64. Weinman, E. J. (Unpublished observations.)

65. Nakajima, K., Clapp, J.R. and Robinson, R. R. Limitations of the shrinking-drop micropuncture technique. Am. J. Physiol., 219: 345,1970 .

66. Bank, N., Koch, K. M., Aynedjian, H. S. and Aras, M. Effect of changes in renal perfusion pressure on the supression of proximal tubular sodium reabsorption due to saline loading. J. Clin. Invest., 48: 271, 1969.

67. Levinsky, N. G., Lalone, R. C. and Arbus, G. S. The split-droplet method and PAH uptake by kidney slices as assay techniques.

In: Regulation of Body Eluid Volumes by the Kidney. Ed. J. H. Cort and B. Lichardus, P. 56, Basel, New York, 1970. S. Karger.

68. Maude, D. L. Stop-flow microperfusion of proximal tubules in rat kidney cortex slices. Am. J. Physiol., 214: 1315, 1968.

69. Bentzel, C. J., Davies, M., Scott, W. N., Zatzman, M. and Solomon, A. K. Osmotic volume flow in the proximal tubule of the Necturus kidney. I. Gen. Physiol., 51: 517, 1968.

70. Wiederholt, M., Langer, K. H., Thoenes, W. and Hierholzer, K. Funktionelle und morphologische Untersuchungen am proximalen und distalen Konvolut der Ratteniere zur Methode der gespalten Olsaule (Split droplet method.) Pflügers Arch. ges. Physiol., 302: 166, 1968. 






\section{YALE MEDICAL LIBRARY \\ Manuscript Theses}

Unpublished theses submitted for the Master's and Doctor's degrees and deposited in the Yale Medical Library are to be used only with due regard to the rights of the authors. Bibliographical references may be noted, but passages must not be copied without permission of the authors, and without proper credit being given in subsequent written or published work.

This thesis by has been

used by the following persons, whose signatures attest their acceptance of the above restrictions. 

